\title{
Cervicothalamic Tract Terminals Are Enriched in Glutamate-like Immunoreactivity: An Electron Microscopic Double-Labeling Study in the Cat
}

\author{
Jonas Broman' and Ole Petter Ottersen² \\ ${ }^{1}$ Department of Cell Biology, Faculty of Health Sciences, University of Linköping, S-581 85 Linköping, Sweden and \\ ${ }^{2}$ Anatomical Institute, University of Oslo, Blindern, N-0317 Oslo, Norway
}

The distribution of glutamate-like immunoreactivity (Glu-LI) in the thalamic ventral posterolateral nucleus (VPL) of cats was studied with the EM immunogold technique in order to identify nerve terminal populations that may use glutamate as a neurotransmitter. The investigation was focused on cervicothalamic tract (CTT) terminals, which were labeled by WGA-HRP transported anterogradely from injection sites in the lateral cervical nucleus (LCN). The amount of Glu-LI in different profiles was evaluated quantitatively by counting the number of gold particles and then calculating the areal density of gold particles over different proflle types.

The highest density of gold particles was found over terminals with morphologic characteristics of terminals of cortical origin (RS terminals), a finding that further supports the glutamatergic nature of these terminals suggested by previous studies. Enrichment of Glu-LI was also found in CTT terminals and in non-peroxidase-labeled terminals with the same morphologic characteristics as CTT terminals (RL terminals). The labeling density over these terminals was about twice the average tissue density of gold particles. The labeling density over large VPL neuronal cell bodies was on average $127 \%$, and that over vesicle-containing dendritic appendages and truncs (presynaptic dendrites) about $80 \%$, of the average tissue density of gold particles. Immunogold labeling with antiserum against glutamine (Gln) indicated low levels of Gin-like immunoreactivity in CTT terminals and a high Glu:Gin ratio as compared to astrocytes and the average Glu:Gin ratio in the VPL.

The present findings provide further support for a transmitter role of glutamate in terminals of ascending somatosensory afferents to the VPL, including the CTT. Taken together with previous findings of an enrichment of Glu-LI in terminals of the spinocervical tract (Broman et al., 1990), our results suggest that synaptic transmission in the spinocervicothalamic pathway is dependent on the release of glutamate both at the levels of the LCN and the VPL.

\footnotetext{
Received May 14, 1991; revised Aug. 13, 1991; accepted Aug. 21, 1991.

This work was supported by the Swedish Medical Research Council (Projects 7879,2710 , and B90-13R-9189), the Norwegian Council for Science and $\mathrm{Hu}-$ manities, the Norwegian Council on Cardiovascular Disease, and the Odd Fellows Research Fund. We thank A. T. Bore, B. A. Fredriksson, J. Knutsen, L. Mackerlova, B. Riber, and T. A. Slyngstad for skillful technical assistance. S. Anderson provided valuable suggestions for linguistic revision.

Correspondence should be addressed to Jonas Broman, Department of Cell Biology, Faculty of Health Sciences, University of Linköping, S-581 85 Linköping, Sweden.

Copyright @ 1992 Society for Neuroscience $0270-6474 / 92 / 120204-18 \$ 05.00 / 0$
}

The ventroposterior nucleus (VP) of the thalamus is a highly somatotopically arranged target for a number of ascending somatosensory pathways and conveys information to cortical areas involved in somatic sensation (Jones, 1985). The VP can be subdivided into a lateral part, the ventral posterolateral nucleus (VPL), representing the body and limbs, and a medial part (VPM) representing the head and face. Somatic sensory information to the VPL is conveyed through three different pathways: the dorsal column-medial lemniscus (DC-ML), the spinothalamic tract (STT), and the spinocervicothalamic pathway (SCTP) (Berkley, 1980). The SCTP is composed of the spinocervical tract (SCT) terminating in the lateral cervical nucleus (LCN) and the cervicothalamic tract (CTT) projecting from the LCN to the VPL (Boivie, 1983). In both cats and primates, the DCML provides the majority of fibers terminating in the VPL, whereas species differences are evident concerning the two other pathways. In cats, the CTT provides a substantial input to the core of the VPL, while the STT terminates mainly in its ventral peripheral part (Boivie, 1970; Berkley, 1980; Burton and Craig, 1983; Craig and Burton, 1985). In monkeys, the STT provides dense patches of termination in the VPL core and the CTT termination is sparser as compared to the cat (Berkley, 1980; Boivie, 1980; Burton and Craig, 1983; Mantyh, 1983).

Although a large number of studies have described the anatomy and physiology of these systems in great detail, knowledge about the neurotransmitter(s) used by the ascending somatosensory pathways is still sparse. That GABA is a neurotransmitter in VPL local circuit neurons and in reticular thalamic neurons projecting to the VPL has been well established, and there is strong evidence for excitatory amino acids, foremost glutamate (Glu), as neurotransmitters in the cortical projection to the VPL (Jones, 1985; Rustioni and Weinberg, 1989). However, electrophysiologic-pharmacologic studies have during recent years suggested that excitatory amino acids may also be involved in synaptic transmission between somatosensory afferents and thalamic neurons (Salt, 1986, 1988; Klockgethcr, 1987; Salt and Eaton, 1989). Immunohistochemical studies have also revealed the presence of glutamate-like immunoreactivity (Glu-LI) in lemniscal-type terminals in the VPL (Rustioni et al., 1988; Spreafico et al., 1989; De Biasi and Rustioni, 1990). It is unclear, however, to what extent such terminals are enriched in Glu-LI as compared to other VPL tissue compartments. A quantitative evaluation of the distribution of Glu-LI in the VPL would be helpful in the investigation of whether Glu is a likely transmitter candidate in somatosensory afferent terminals.

Previous reports have described the location of several neu- 
roactive substances in the LCN (Blomqvist et al., 1985a; Giesler and Elde, 1985; Broman and Westman, 1988; Broman and Blomqvist, 1989a,b, 1990; Maxwell et al., 1989) including an enrichment of Glu-LI in SCT terminals (Broman et al., 1990). However, the findings in these studies do not give any evidence regarding the neurotransmitter used by the CTT neurons. In the present study, immunohistochemical labeling with an antiserum against glutaraldehyde-fixed Glu and colloidal gold-labeled secondary antibodies were used for evaluating the distribution of Glu-LI in CTT terminals and other cellular compartments in the VPL.

\section{Materials and Methods}

Animals and tissue preparation. To identify CTT terminals in the VPL, the terminals were labeled by WGA-HRP transported anterogradely from injection sites in the LCN of three cats. The cats were anesthetized with xylazine ( $3 \mathrm{mg} / \mathrm{kg}$, i.m.) and sodium pentobarbital $(40 \mathrm{mg} / \mathrm{kg}$, i.p.), and the first and second cervical segments of the spinal cord were uncovered by a dorsal laminectomy. Injections of WGA-HRP (5\%; Sigma) into the LCN were made with a glass micropipette attached to a Ilamilton syringe. The micropipette was inserted through the dorsolateral funiculus of segments $\mathrm{Cl}$ and $\mathrm{C} 2$ at an angle of about $30^{\circ}$ with the sagittal plane, and a total amount of $0.05-0.15 \mu \mathrm{l}$ of WGA-HRP was delivered to each cat through several rostrocaudally spaced penetrations.

After a survival period of $2 \mathrm{~d}$, the cats were anesthetized deeply with sodium pentobarbital and killed by transcardial perfusion. After a short rinse $(10 \mathrm{sec})$ with $300 \mathrm{mOsm}$ PBS ( $\mathrm{pH} \mathrm{7.4,} \mathrm{at} \mathrm{room} \mathrm{temperature)}$ containing $4000 \mathrm{IU}$ heparin/liter, the cats were perfused for $45 \mathrm{~min}$ with 3.5-4.0 liters of a fixative containing $2 \%$ glutaraldehyde and $1 \%$ paraformaldehyde in PBS ( $\mathrm{pH} 7.4,4^{\circ} \mathrm{C}$ ). The perfusion was terminated with a rinse with $1-2$ liters of cold PBS.

To limit a possible release and redistribution of amino acids due to hypoxia (Benveniste et al., 1984), the time used for thoracotomy and prefixation rinsing was kept as short as possible. All animals showed signs of fixation (neck rigidity) within $90 \mathrm{sec}$ of thoracotomy.

The upper part of the spinal cord containing the injection sites was removed and placed in $30 \%$ sucrose in PBS at $4^{\circ} \mathrm{C}$ overnight and then cut transversely into $40-\mu$ m-thick sections on a freezing microtome. One section out of five was processed with $p$-phenylenediamine-pyrocathecol (Hanker et al., 1977) to visualize the injection sites, and mounted on slides.

The brain was stored in PBS at $4^{\circ} \mathrm{C}$, overnight. The thalamus contralateral to the injection site was then cut on a Vibratome in the frontal plane into $50 \mu \mathrm{m}$ sections that were sampled in groups of three sections. One of the sections in each group was mounted and stained with thionin. The second section in each group was processed with tetramethylbenzidine (TMB) at pH 3.3 according to Mesulam (1982) and mounted for light microscopic examination.

For electron microscopic visualization of TMB reaction product, the third section in each group was processed at $\mathrm{pH} 6.0$ according to two different protocols. In two of the cats, the sections were processed in citric acid-ammonium acetate buffer according to Schönitzer and Holländer (1981) with nitroferricyanide as the stabilizing agent. These sections were osmicated in $1 \% \mathrm{OsO}_{4}$ in $\mathrm{PBS}$ at $\mathrm{pH} 7.4$ for $20 \mathrm{~min}$. In the third cat, the sections were processed in $0.1 \mathrm{M}$ phosphate buffer (PB) with ammoniumheptamolybdate as stabilizing agent (Olucha et al., 1985; Ralston et al., 1988). The sections processed according to this latter protocol were soaked in $1 \% \mathrm{OsO}_{4}$ in $\mathrm{PB}\left(\mathrm{pH} 5.5,4^{\circ} \mathrm{C}\right.$ ) overnight (Henry et al., 1985).

After rinsing in PBS, the sections processed according to both protocols were dehydrated in graded alcohols, embedded in Durcupan (ACM, Fluka), and cured for $48 \mathrm{hr}$ at $56^{\circ} \mathrm{C}$. Areas in the core of the VPL containing TMB reaction product were trimmed out with razor blades, and serial sections for immunogold labeling and electron microscopic examination were cut on an ultramicrotome and mounted on Formvarcoated one-hole nickel grids (one section per grid).

Electron microscopic immunohistochemistry. The procedure used for postembedding immunogold staining of ultrathin sections was based on that of Somogyi and Hodgson (1985) and modified to include the following steps: (1) $1 \% \mathrm{HIO}_{4}$ in distilled water $(10 \mathrm{~min}) ;(2) 5 \% \mathrm{NaIO}_{4}$ in distilled water (60 min); (3) 1\% human serum albumin (HSA) in distilled water (15 min); (4) Glu antiserum 03 [Glu03; raised by Storm-Mathisen et al., 1983; characterized at the EM immunogold level by Maxwell et al. (1990), Zhang et al. (1990), and Ji et al. (1991)] diluted 1:1000 in Tris-phosphate-buffered saline ( $\mathrm{pH} 7.4)$ containing $1 \% \mathrm{HSA}(18-20 \mathrm{hr}$ ); to alleviate cross-reactivity with glutamine (Gln) and aspartate (Asp), $100 \mu \mathrm{M}$ each of glutaraldehyde fixation complexes of these amino acids were added to the diluted antiserum the day before use (Ottersen et al., 1986); (5) polyethyleneglycol (50 mg/100 ml $0.05 \mathrm{M}$ Tris buffer, $\mathrm{pH} 7.4$, $20 \mathrm{~min}$ ); (6) goat anti-rabbit IgG coupled to colloidal gold particles (15 $\mathrm{nm}$; BioCell), diluted 1:20 in the solution used in the previous step (2 $\mathrm{hr}$ ); and (7) uranyl acetate ( $20 \mathrm{~min}$ ) followed by lead citrate (1-3 min) All incubations were performed in humid chambers. In steps $1-4$, the sections were immersed in drops of the different reagents. From step 5 and on, the grids were floated on top of the reagents with the section down (the Formvar coating unspecifically attracts gold particles, and incubation of Formvar-coated grids in drops of colloidal gold would thus increase background labeling through binding of gold particles to the Formvar coating opposite the section). Control sections and graded sections (see below) were mounted on mesh nickel grids without Formvar coating and were therefore kept immersed throughout the immunohistochemical procedure. The sections were rinsed in buffer or distilled water between all steps except between steps 3 and 4 and steps 5 and 6.

Although the Glu antiserum was treated with glutaraldehyde fixation complexes of Gln before use, slight cross-reactivity with Gln still remained in the present experiments (see Results). To evaluate to what extent the cross-reactivity may have influenced the immunogold labeling for Glu, sections adjacent to those incubated in Glu antiserum were in some cases processed with Gln antiserum 34 [Gln34; raised by Laake et al., 1986; characterized at the EM immunogold level by Zhang et al. (1991) and Ottersen et al. (1991)]. The procedure was identical to that described above except that Glu03 was replaced with $G \ln 34$ (1:1000) and glutaraldehyde fixation complexes with Gln were replaced with Glu complexes.

Specificity controls. The antisera used have previously been screened in "spot tests" against brain macromolecule-glutaraldehyde complexes of more than 40 different small molecules endogenous to the brain and found to react selectively with fixed Glu and Gln, respectively (Ottersen and Storm-Mathisen, 1984; Laake et al., 1986). The specificity of the postembedding immunogold labeling was monitored in the present experiments by parallel incubation of "control sections" containing Durcupan-embedded brain macromolecule-glutaraldehyde fixation complexes of the six most abundant amino acids in the brain (Ottersen, 1987).

Additional controls included processing of ultrathin sections from the VPI, with omission of primary antiserum or in antiserum that had been preabsorbed overnight with glutaraldehyde fixation complexes of the respective amino acid $(300 \mu \mathrm{M}$, concentration with respect to the amino acid). In these control experiments, the neuropil contained only a few scattered gold particles with a density comparable to that seen over empty resin.

To evaluate the relationship between gold particle density and concentration of fixed Glu, a section containing a series of brain macromolecule-glutaraldehyde conjugates prepared with different concentrations of Glu ("'graded section"; Ottersen, 1989a,b; Bramham et al., 1990) was included in each Glu immunogold experiment.

Quantitative evaluation of gold particle density. Quantitative evaluation of the gold particle density over different neuronal profiles was performed on three Glu immunogold-labeled ultrathin sections cut from three different Vibratome sections through the VPL in each cat. The sections were in all cases cut from the core of the VPL, excluding terminal labeling in peripheral parts of the nucleus and in the laminae separating the lateral and medial parts of VPL (VPLI-VPLm) and VPLVPM (see Results). In each section, the gold particle density over eight peroxidase-positive CTT terminals was calculated.

Electron microscopic examination of immunogold-labeled ultrathin sections from the VPL showed a diminished visibility of the TMB reaction product as compared to non-immunogold-labeled sections. Therefore, and in order to avoid a bias in the selection of terminals in relation to their gold labeling density, the peroxidase-positive CTT terminals to be analyzed were first identified in a section that had not been processed for immunogold labeling and then the terminal was photographed in the adjacent immunogold-labeled section. As preliminary observations indicated that dense peroxidase labeling disrupting the internal structure of terminals lowered the density of gold particles, such terminals were not selected for further analysis. Selected terminals were 
rejected only if their analysis of gold particle density was compromised by lead precipitates or other artifacts.

In addition to CTT terminals, the density of gold particles was calculated over certain other neuronal profiles in each scction. The other synaptic vesicle-containing profiles analyzed were identified on morphologic criteria according to Ralston $(1983,1985)$. Like the CTT terminals, these profiles were identified in a non-immunogold-labeled section and then photographed in the adjacent immunogold-labeled section. The analyzed vesicle-containing profiles include (1) $R L$ (round large) terminals, large terminals containing rounded vesicles, similar in appearance to the CTT terminals but not containing TMB reaction product; the appearance of these terminals corresponds to that of ascending afferents from the dorsal column nuclei (DCN), the LCN, and the spinal cord (Ralston, 1983; Blomqvist et al., 1985b); (2) $R S$ (round small) terminals, whose appearance corresponds to terminals of cortical origin (Jones, 1985; Ralston, 1985); (3) PSDs (presynaptic dendrites), vesiclecontaining dendritic appendages or dendritic truncs of GABAergic local circuit neuron origin (Penny et al., 1983; Spreafico et al., 1983; Ralston, 1985; Ralston et al., 1988). For each type, the density of gold particles was calculated for eight profiles in each section.

The density of gold particles was also analyzed over the cytoplasm of four large neuronal cell bodies in each section. The mean gold particle density over the VPL was calculated from eight random electron micrographs (each covering about $10 \mu \mathrm{m}^{2}$ ) in each section. Background levels of gold particle density $\left(0.2-1.2\right.$ gold particles $\left./ \mu \mathrm{m}^{2}\right)$ were measured over resin devoid of tissue, such as lumen of blood vessels, and subtracted from the different values of tissue labeling. Also analyzed was the gold particle density over the different brain macromolecule-glutaraldehyde-amino acid conjugates in control sections and graded sections incubated together with VPL sections.

For comparison of Glu-LI and Gln-like immunoreactivity (Gln-LI), the density of gold particles over eight CTT terminals and eight astroglial cells (the glial cells were among the structures most densely labeled by the Gin antiserum) were analyzed in two adjacent sections, one processed with Glu antiserum and the other with Gln antiserum. The mean gold particle density over the VPL in both sections was calculated from random micrographs as described above.

Gold particle densities over neuronal profiles, random micrographs, and amino acid conjugates were assessed from electron micrographic negatives (magnification, 15,000 $\times$ ) projected with a photographic reproduction equipment (Durst Varipoint 1200, Bressanone, Italy) to yield a final magnification of $48,000 \times$. Areas were drawn on sheets of paper and then calculated on a digitizer connected to a computer. The numbers of gold particles were counted and entered manually from the keyboard. The computer program used in the analysis (MORFOREL) has been described previously (Blackstad et al., 1990).

\section{Results}

\section{Injection sites and anterograde labeling in the thalamus}

The injection sites were in all cases situated in the dorsolateral funiculus in or close to the LCN (Fig. 1 $A$ ). In all cases, there was also a varying spread of injected WGA-HRP to the adjacent gray substance in the dorsal and ventral horns on the ipsilateral side but never to the contralateral side. None of the tracer injections encroached upon the DCN.

The terminology and delineation of nuclei in the thalamus follow that previously used by other authors investigating the termination of the CTT (Boivie, 1970; Berkley, 1980; Blomqvist et al., 1985b). In the thalamus, dense anterograde labeling was found in the VPL in all cats (Fig. $1 B, C$ ). The labeling was organized in patches seen in all parts of the VPL, but the densest labeling was present in its dorsolatcral portions. Antcrograde labeling was also seen along the ventral periphery of the VPL as well as in and adjacent to the laminae separating the VPLI and VPLm, and VPL and VPM. At caudal levels of the VPL, less dense anterograde labeling was seen as patches in the medial division of the posterior nuclear group (POm) dorsal and medial to the main terminal area in the VPL. In the posterior part of the thalamus, caudal to the VPL, anterograde labeling was also consistently found in the border zone between the PO and the magnocellular part of the medial geniculate nucleus (MGmc) (Fig. 1D).

In one of the cats, in which the injections of WGA-HRP showed pronounced involvement of the dorsal horn, anterograde labeling was also seen in the nucleus submedius (Sm). In the other cats, in which the injections showed lesser involvement of the dorsal horn, no labeling was found in Sm. No labeling was found in other medial thalamic structures, including the intralaminar nuclei, in any of the cats.

EM examination of sections from the VPL showed that TMB reaction product was present in terminals and myelinated axons (Fig. $2 A$ ). The terminals labeled by the peroxidase reaction will in the following be referred to as CTT terminals. These terminals were often large and contained rounded synaptic vesicles and mitochrondria. They had asymmetric synaptic contacts with vesicle-containing dendritic appendages (PSDs) and with dendrites not containing vesicles (Fig. $2 A, B$ ). In the latter case, synapses were seen both with dendritic shafts and with dendritic appendages. Often the CTT terminals were seen apposing or having synaptic contacts with several dendritic profiles in a single section. CTT terminals in synaptic contact with the soma of neuronal cell bodies were also found (Fig. 2C), but this arrangement was infrequent in comparison to axodendritic synapses. Triadic synaptic arrangements involving CTT terminals were found (Fig. $2 D$ ) but appeared to be infrequent by the present single-section analysis. Analysis in serial sections would probably reveal a higher proportion of CTT terminals with this synaptic arrangement.

\section{Comparison of glutamate- and glutamine-like imunoreactivity}

The control sections incubated together with tissue sections in Glu antiserum showed high densities of gold particles over the Glu conjugates (Fig. 3, Table 1). However, although the antiserum had been treated with Gln-glutaraldehyde complexes prior to use, slight cross-reactivity with Gln still remained. The density of gold particles over the Gln conjugates was $6.8-7.7 \%$ of that over the Glu conjugates (Table 1) and significantly different from that over the None conjugates (brain macromolecule-glutaraldehyde conjugates without amino acids). In order to evaluate to what extent the cross-reactivity with Gln may have affected the immunogold labeling for Glu, a comparison was made between the labeling patterns seen in adjacent ultrathin sections incubated in Glu and Gln antisera, respectively.

Control sections incubated in Gln antiserum showed a dense and selective immunogold labeling of the Gln conjugate, and the densities of gold particles over the other amino acid conjugates were low and not significantly different from that over the None conjugate (Table 1). In sections from the VPL, gold particles indicating the presence of Gln-LI were seen throughout the tissue and found over most tissue compartments, although in different densities. Astroglial cells were among the most densely labeled structures, whereas a low density of gold particles was seen over most synaptic vesicle-containing profiles. The density of gold particles over neuronal cell bodies was higher than that over nerve terminal profiles. Also in Glu-immunogold-labeled sections, gold particles were seen over most tissue compartments, but the distribution was different from that of Gln-LI. High levels of Glu-LI were seen in nerve terminal profiles containing round vesicles, and intermediate levels occurred over neuronal cell bodies, whereas the density of gold particles over astrocytes was low. Figure 4 shows the profiles of a CTT terminal 


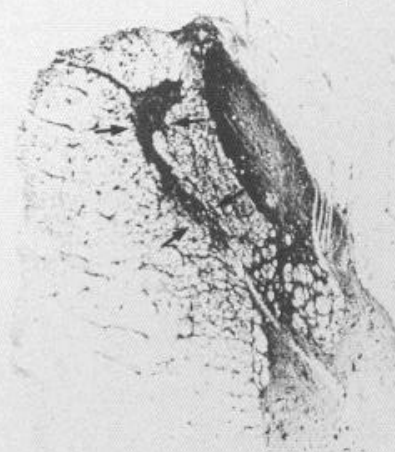

A
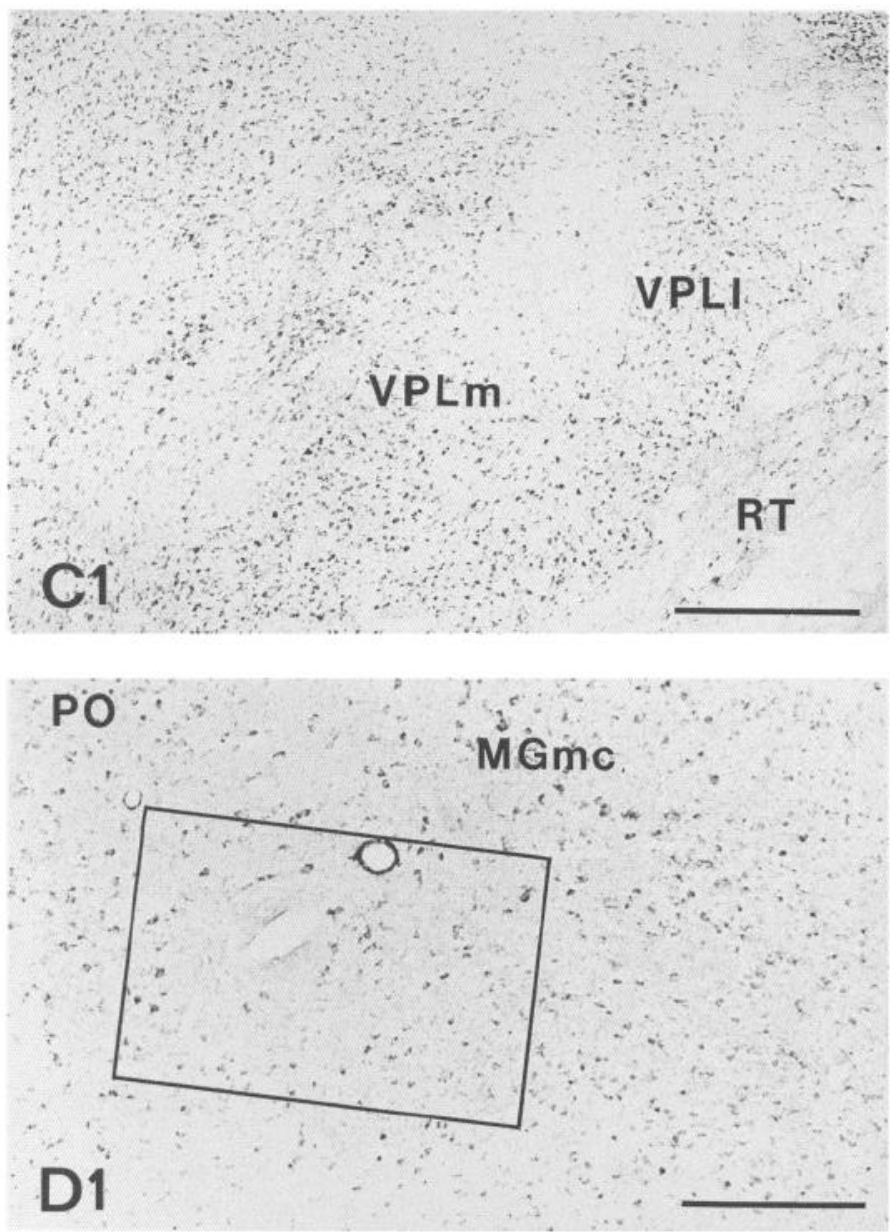
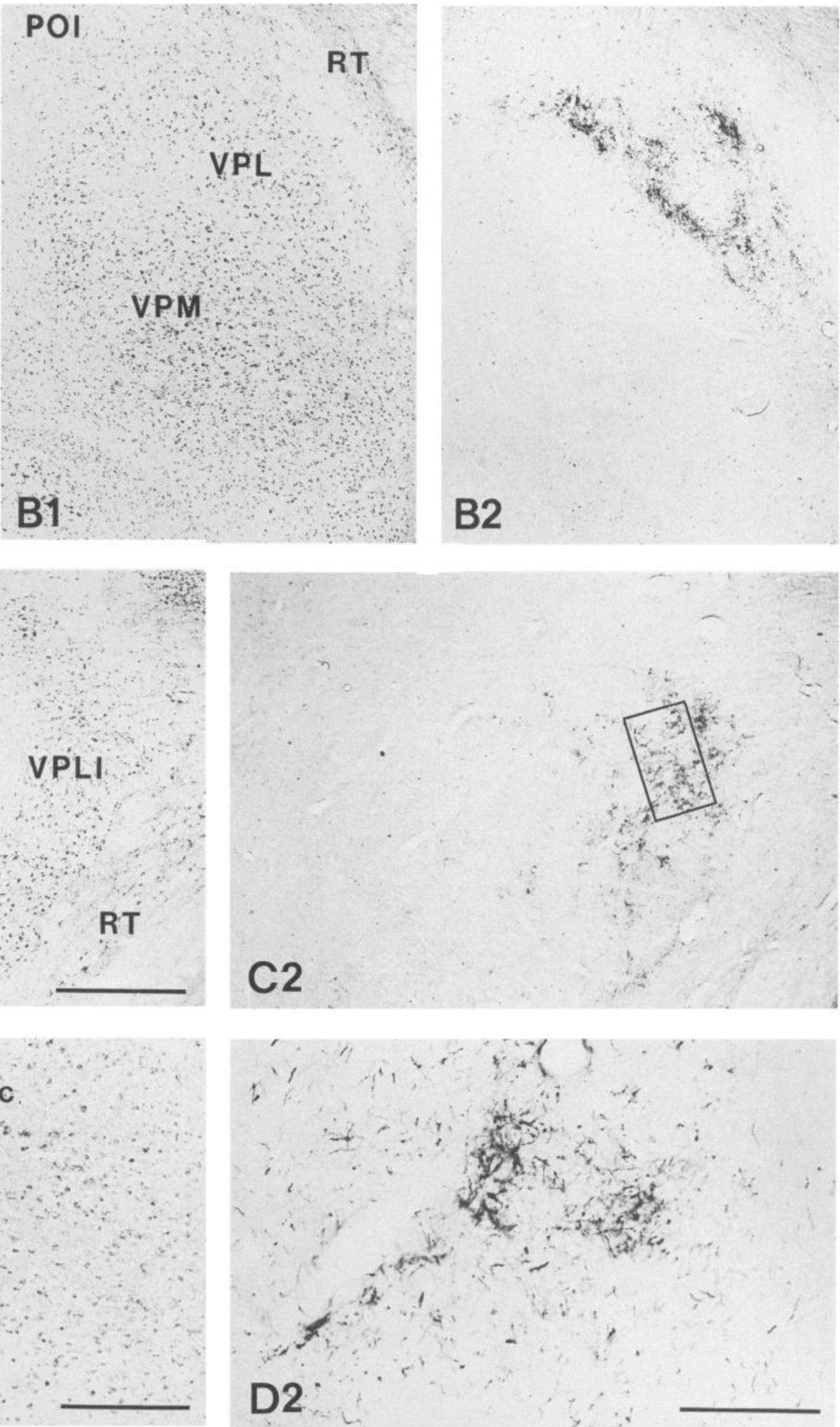

Figure 1. Light micrographs of WGA-HRP injection into the LCN and anterograde labeling in the thalamus. $A$, Injection site in the dorsolateral funiculus with dense labeling of the LCN (arrows). The injection also involves adjacent gray substance. B1, Thionin-stained section from the thalamus of the cat receiving the WGA-HRP injection shown in $A$. Dorsal is to the left and lateral is upward. $B 2$, Corresponding area in the TMBprocessed section adjacent to the section in $B 1$. Anterograde labeling is seen in the VPL. $C 1$ and $C 2$, Light micrographs of adjacent sections from the thalamus rostral to those shown in $B$. Dorsal is upward and lateral is to the right. Anterograde labeling is seen in the VPL, with the densest labeling in its dorsolateral part. The rectangle in $C 2$ exemplifies how areas in the VPL core were selected for ultrathin sectioning. D1 and D2, Micrographs of adjacent sections from the posterior part of the thalamus. Dorsal is upward and lateral is to the right. The area of $D 2$ is indicated by a rectangle in $D 1$. Anterograde labeling is seen in the border zone between $M G m c$ and $P O$. Abbreviations: MGmc, magnocellular division of the medial geniculate nucleus; $P O$, posterior nuclear group ( $l$, lateral division); $V P L$, ventral posterolateral nucleus $(l$, lateral division; $m$, medial division); $V P M$, ventral posteromedial nucleus; $R T$, thalamic reticular nucleus. Scale bars: $A$ (also valid for $B 1$ and $B 2$ ), and $C 1$ (also valid for $C 2$ ), $1 \mathrm{~mm} ; D 1,0.5 \mathrm{~mm} ; D 2,0.25 \mathrm{~mm}$. 

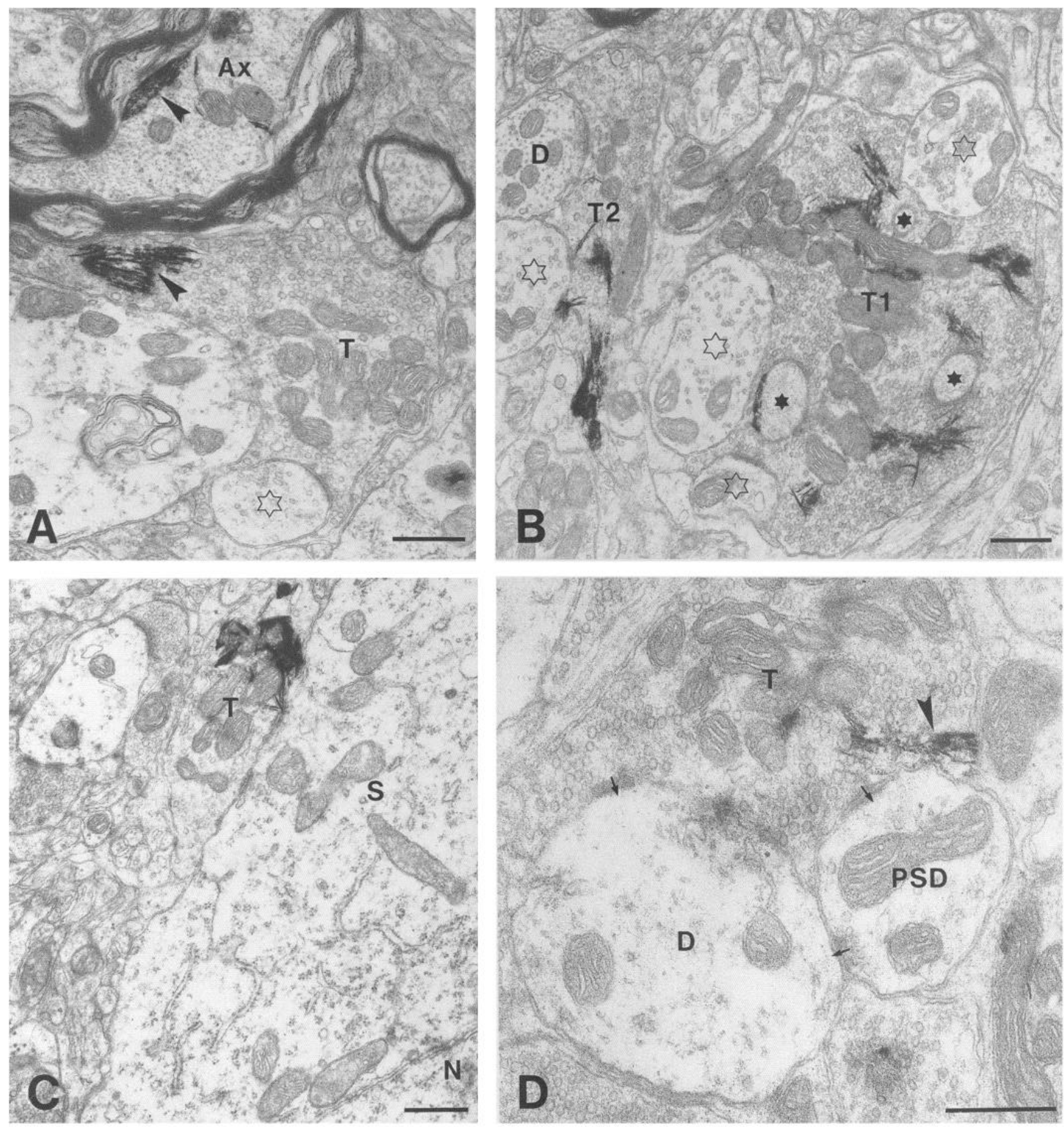

Figure 2. Electron micrographs of peroxidase-labeled axons and terminals in the VPL after WGA-HRP injections into the LCN. A, Peroxidaselabeled myelinated axon $(A x)$ and axon terminal $(T)$; the peroxidase reaction product is indicated by arrowheads. The terminal is in synaptic contact with a vesicle-containing dendritic appendage (open star). $B$, Two peroxidase-positive terminals $(T 1, T 2)$. $T 1$ surrounds three dendritic protrusions (solid stars), and three apposing vesicle-containing dendritic appendages (PSDs, open stars) are seen at the periphery of the terminal. The PSD at the bottom of the panel is postsynaptic to $T 1$. T2 is in synaptic contact with a PSD (open star) and a dendritic profile (D) that does not contain synaptic vesicles. $C$, Peroxidase-labeled axon terminal $(T)$ in synaptic contact with the soma $(S)$ of a neuronal cell body. A part of the nucleus $(N)$ is seen at the lower right. $D$, High-power electron micrograph showing a peroxidase-labeled (arrowhead) axon terminal $(T)$ that is involved in a triadic synaptic arrangement with a presynaptic dendrite $(P S D)$ and a dendrite $(D)$ not containing synaptic vesicles. Synaptic sites are indicated with small arrows. Scale bars, $0.5 \mu \mathrm{m}$. 

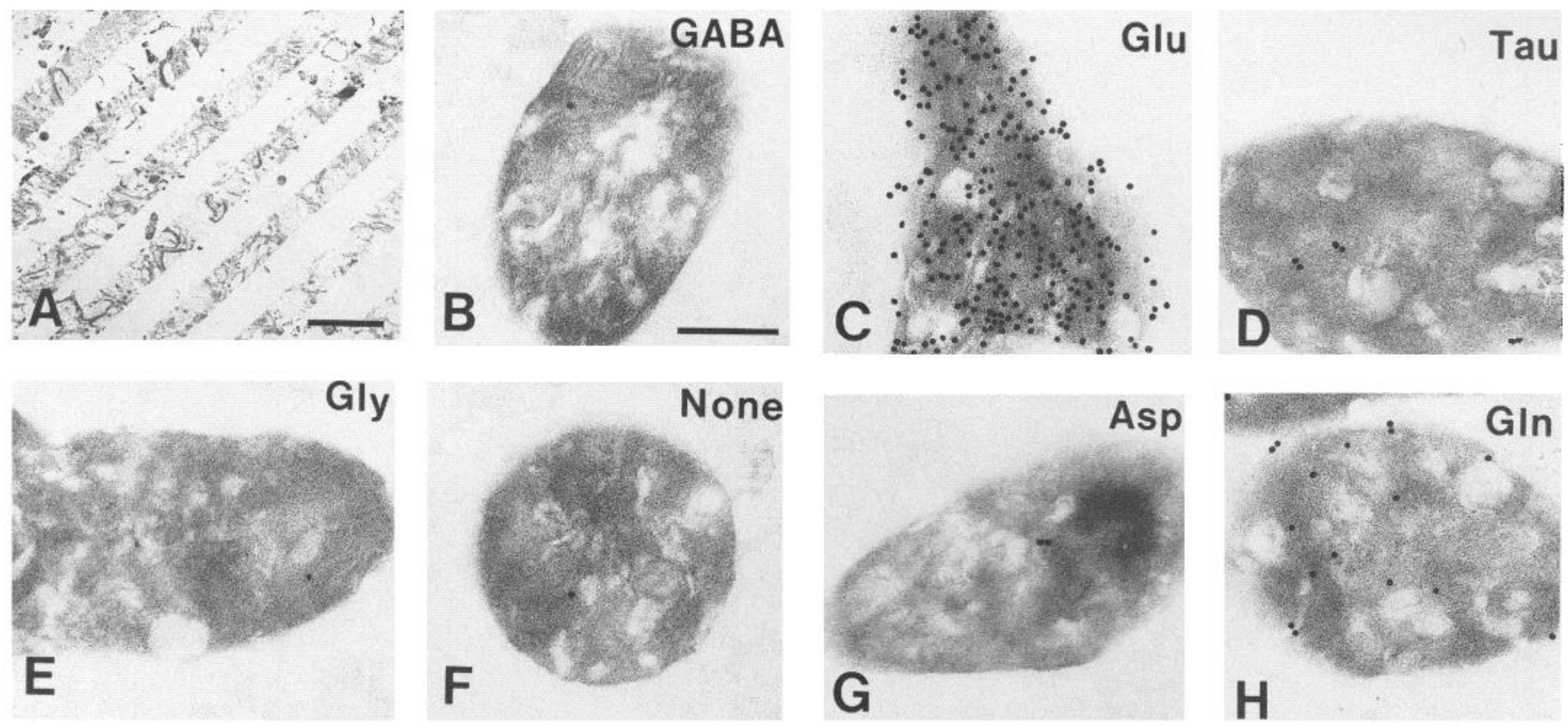

Figure 3. Electron micrographs of a control section included in one of the present experiments. A, Low-power electron micrograph showing an overview of the control section. The light stripes contain clumps of the different amino acid-glutaraldehyde-brain macromolecule conjugates. The darker stripes are tissue sections used as spacers between conjugates (for details on preparation of control sections, see Ottersen, 1987). $B-H$, Highpower electron micrographs of the different conjugates (None, glutaraldehyde-treated brain macromolecules without addition of amino acid). Note the high density of gold particles over the Glu conjugate $(C)$. A slight cross-reactivity with $\mathrm{Gln}(H)$ is evident, while the other conjugates are virtually unlabeled. For quantitative data, see Table 1. Scale bars: $A, 5 \mu \mathrm{m} ; B$ (also valid for $C-H$ ), $0.25 \mu \mathrm{m}$.

and an astrocyte in adjacent sections labeled with Glu and Gln antiserum, respectively.

A quantitative evaluation comparing the density of gold particles in two adjacent sections incubated in Glu and Gln antiserum was made. The gold particle density over eight CTT terminals, over the cytoplasm of eight astrocytes, and over eight random micrographs was calculated in each section (the profiles of the same terminals and astrocytes in both sections were analyzed). The results are shown in Figure 5. Whereas in the Glu immunogold-labeled section the CTT terminals had a high, and the astrocytes a low, density of gold particles, the situation was the opposite in the section processed with Gln antiserum.

In the control section processed with Gln antiserum, the den- sity of gold particles over the Gln conjugate, which is produced from a high concentration of Gln (Ottersen, 1987), was 693.4/ $\mu \mathrm{m}^{2}$. In the tissue section incubated together with the control section in Gln antiserum, the labeling of astrocytes was on average 34.2 gold particles $/ \mu \mathrm{m}^{2}$. The density of gold particles over the Gln conjugates in the control section incubated in Glu antiserum was $42.9 / \mu \mathrm{m}^{2}$. In relation to the figures above, the crossreactivity with Gln would thus give a density of about 2 gold particles $/ \mu \mathrm{m}^{2}$ over astrocytes in the Glu immunogold-labeled section $(34.2 / 693.4=A / 42.9 ; A=2.1)$. As the labeling of astrocytes in the tissue section incubated in Glu antiserum on average was 14.0 gold particles $/ \mu \mathrm{m}^{2}$, the cross-reactivity with Gln would account for about $15 \%$ of the labeling density seen

Table 1. Densities of gold particles over different amino acid conjugates in control sections used for evaluation of immunogold labeling specificity $\left(n / \mu \mathrm{m}^{2}\right)$

\begin{tabular}{lcccc} 
& $\begin{array}{l}\text { Experiment I } \\
(\text { Glu })\end{array}$ & $\begin{array}{l}\text { Experiment II } \\
(\text { Glu })\end{array}$ & $\begin{array}{l}\text { Experiment III } \\
\text { (Glu) }\end{array}$ & $\begin{array}{l}\text { Experiment IV } \\
\text { (Gln) }\end{array}$ \\
\hline GABA & $6.2(4.4)$ & $8.8(6.1)$ & $3.5(1.7)$ & $4.8(1.9)$ \\
Glu & $367.2(28.0)^{*}$ & $772.0(48.0)^{*}$ & $557.1(41.0)^{*}$ & $3.8(3.2)$ \\
Tau & $3.6(2.8)$ & $5.2(1.3)$ & $4.5(1.5)$ & $6.7(3.8)$ \\
Gly & $2.9(1.1)$ & $6.7(2.5)$ & $7.3(2.6)$ & $4.1(1.3)$ \\
None & $6.2(3.7)$ & $3.1(2.3)$ & $4.5(1.6)$ & $11.2(6.2)$ \\
Asp & $2.0(1.1)$ & $14.4(1.9)$ & $12.1(2.9)$ & $6.0(2.5)$ \\
Gln & $24.9(3.0)^{*}$ & $53.8(2.6)^{*}$ & $42.9(4.9)^{*}$ & $693.4(65.5)^{*}$
\end{tabular}

The control sections were prepared from Durcupan-embedded amino acid-glutaraldehyde-brain macromolecule conjugates (for details on preparation, see Ottersen, 1987). One control section was included in each immunogold labeling experiment. In experiments I-III, the control sections were processed together with sections from the VPL in glutamate antiserum (Glu03), and in experiment IV, in glutamine antiserum (Gln34). Eight conjugate profiles were analyzed for each amino acid conjugate in each section. The values within parentheses represent SEM. Asterisks indicate significant differences as compared to the None conjugate (glutaraldehyde-treated brain macromolecules without addition of amino acid; Wilcoxon's signed rank test, $p<0.02$ ). 

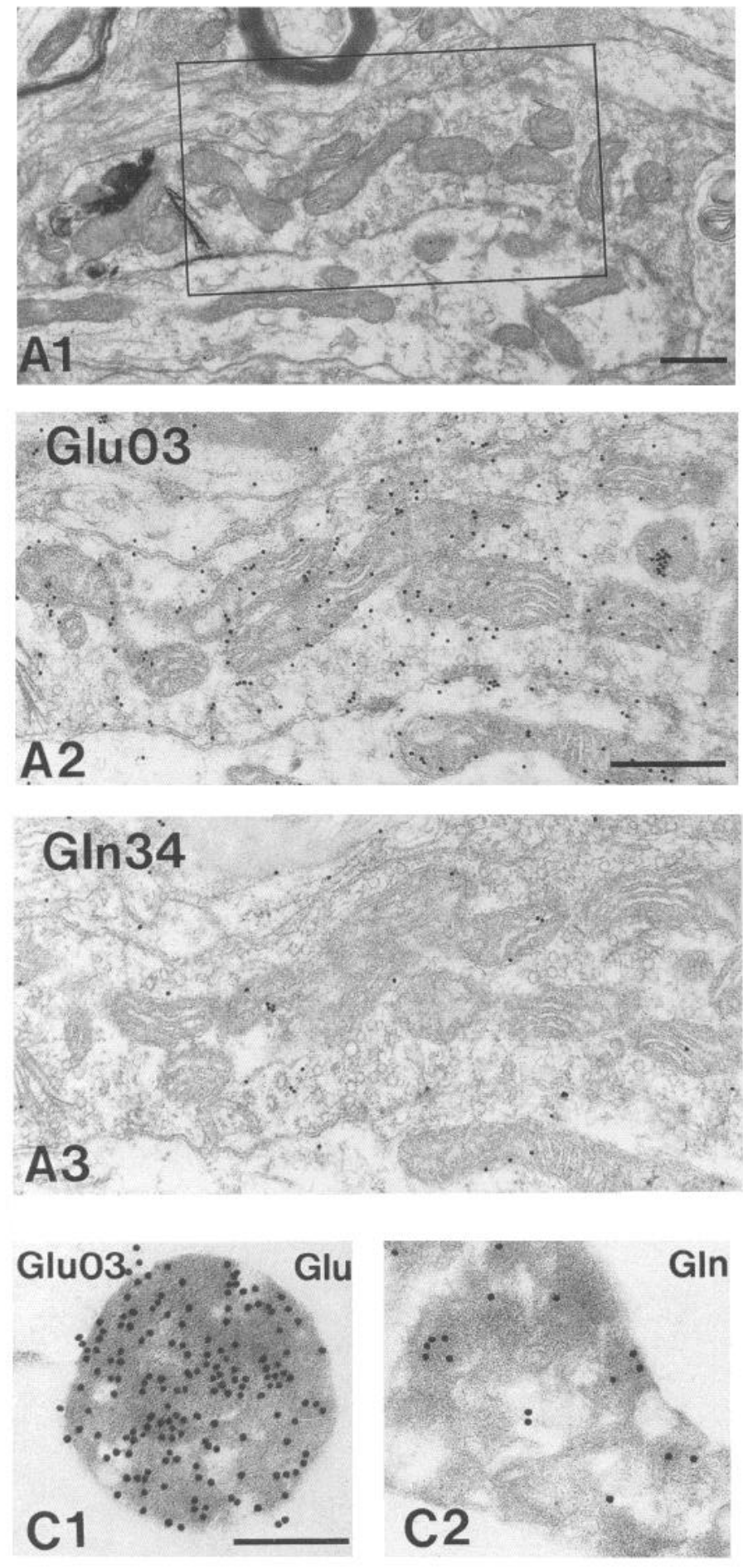
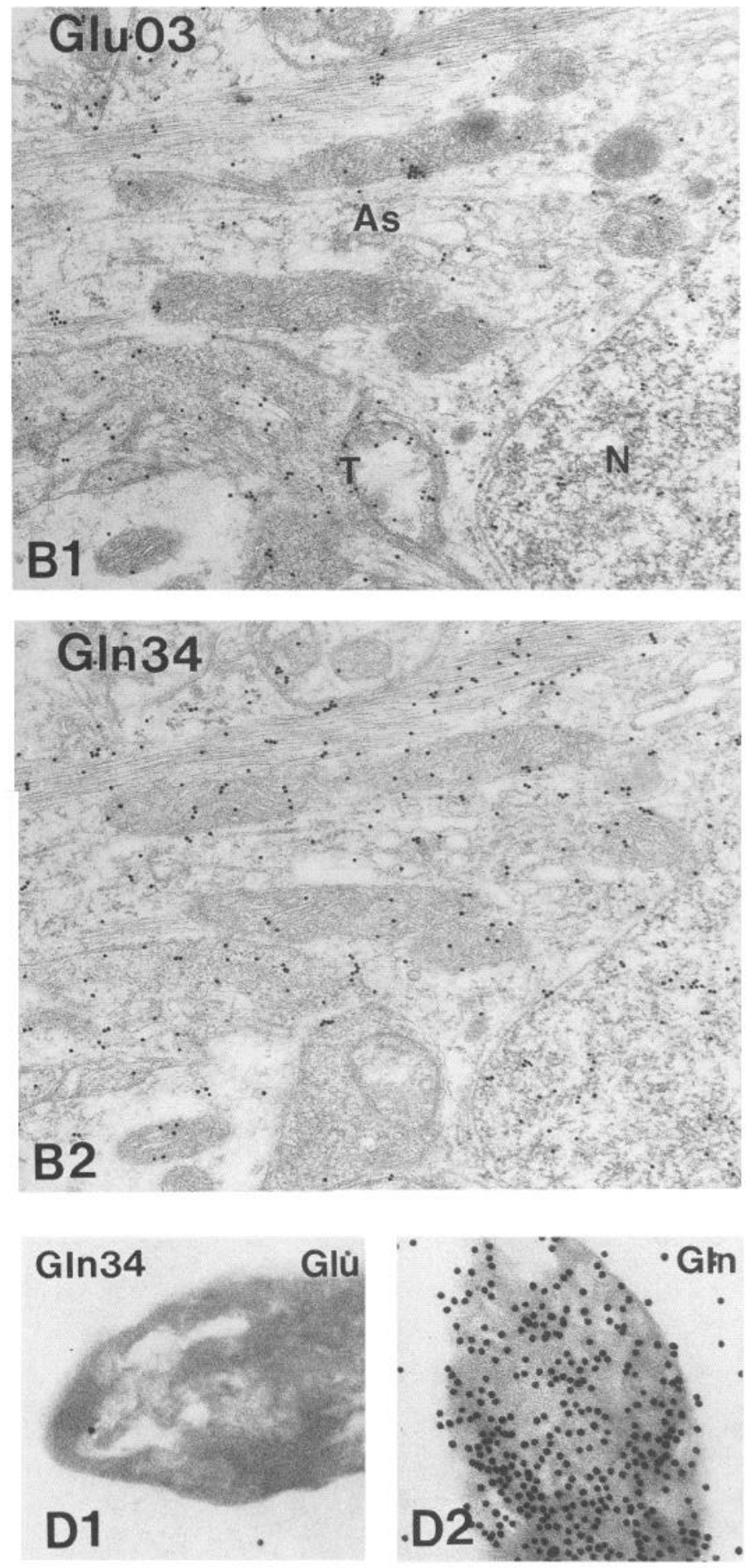

Figure 4. Electron micrographs comparing Glu-LI and Gln-LI in the VPL. $A 1-A 3$ show a peroxidase-labeled CTT terminal in three adjacent sections. The rectangle in $A 1$ indicates the area shown in $A 2$ and $A 3$. In $A 2$, the CTT terminal is shown to be densely labeled by the Glu antiserum (Glu03), while only sparse labeling of the terminal is evident with the Gln antiserum $(G \ln 34, A 3)$. In $B 1$ and $B 2$, micrographs taken from the same sections as $A 2$ and $A 3$, the cytoplasm of an astrocyte $(A s)$ and its nucleus $(N)$ is sparsely labeled by Glu03 and more densely labeled by Gln34. The situation is the reverse for the nerve terminal $(T)$. $C$ and $D$ show Glu and Gln conjugates in the control sections incubated together with the tissue sections in $A 2, A 3, B 1$, and $B 2$. Scale bars: $A 1$ and $A 2,0.5 \mu \mathrm{m}$ (bar in $A 2$ also valid for $A 3, B 1$, and $B 2$ ); $C 1,0.25 \mu \mathrm{m}$ (also valid for $C 2, D 1$, and D2).

over astrocytes in Glu immunogold-labeled sections (2.1/14.0 $=0.15$ ). If a similar calculation is made for the average density of gold particles over the VPL tissue, the cross-reactivity with Gln would increase the labeling for Glu-LI with about $3 \%$. For
CTT terminals, which contained very low levels of Gln-LI, the effect of the cross-reactivity on gold particle density would be less than $1 \%$. In conclusion, the cross-reactivity with Gln showed by the Glu antiserum probably increases the labeling density 
Glutamate-like immunoreactivity

Glutamine-like immunoreactivity

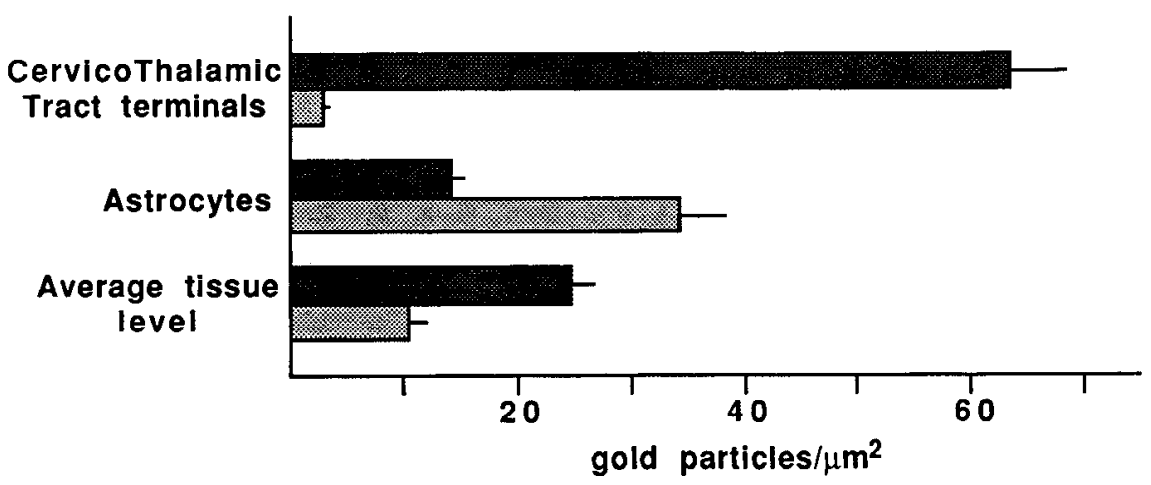

GLU

$\overline{G L N}$
Figure 5. Histogram showing a comparison between Glu-LI and Gln-LI. The profiles of eight CTT terminals and the cytoplasm of eight astrocytes were analyzed in adjacent sections labeled with Glu and Gln antiscrum, respectively (the same terminals and astrocytes were analyzed in both sections; compare Fig. 4). The average tissue density of gold particles was calculated from eight random micrographs in both sections. Error bars indicate SEM. The ratios between Glu-LI and GIn-LI are given to the right. Note the large difference in Glu:Gln ratio between CTT terminals and astrocytes. somewhat over Gln-rich structures such as astrocytes but has negligible effects on the general staining pattern and does not invalidate the results and conclusions given below regarding the distribution of Glu-LI in the VPL.

\section{Glutamate-like immunoreactivity in the VPL}

In sections from the VPL processed for Glu immunogold labeling, gold particles were seen in varying densities over most tissue compartments (Fig. 6). Round vesicle-containing profiles were more densely labeled than those containing pleomorphic vesicles. Over large neuronal cell bodies, the density of gold particles was relatively high and exceeded that seen over astrocytic cell bodies and processes. A varying density of gold particles was seen over myelinated axons and dendritic profiles devoid of synaptic vesicles. The peroxidase-positive CTT terminals were more densely labeled by gold particles than most other structures in the surrounding neuropil (Fig. 7).

The results of the quantitative evaluation of gold particle density are given in Table 2 , and examples of the labeling density over the structures analyzed are shown in Figure 8 . The general density of gold particles varied between the sections analyzed, probably due to small differences in incubation parameters. However, the relation between the different structures in terms of relative gold particle density was similar in all sections. To allow a comparison of the results from the different sections from one animal and between animals, the values for gold particle density over the different structures were normalized (for description of the procedure, see Fig. 9 caption). Normalized values express the gold particle density for a particular structure as a percentage of the mean gold particle density for all structures analyzed in the section.

The results of this operation are summarized in Figure 9. The values for normalized mean gold particle density over the different structures were similar in all three cats, and the order of labeling density for different structures was the same (Fig. 9A). The highest mean density of gold particles was present over RS terminals, and the lowest was over PSDs, over which the labeling was below the tissue average. The density of gold particles over neuronal cell bodies was slightly higher than the tissue average. The CTT and RL terminals had similar mean density of gold particles, being about twice the average tissue labeling. Statistical comparison showed that the average tissue density of gold

Table 2. Mean densities of gold particles over different structure types in different VPL sections processed with antiserum against glutamate $\left(n / \mu \mathrm{m}^{2}\right)$

Cat/

Section

Exp

\begin{tabular}{lllrlr} 
CTT & RL & RS & \multicolumn{1}{l}{ PSD } & \multicolumn{1}{l}{ CB } & \multicolumn{1}{l}{$\begin{array}{l}\text { Tissue } \\
\text { average }\end{array}$} \\
\hline $41.2(4.2)$ & $46.0(2.9)$ & $56.9(8.1)$ & $14.0(2.5)$ & $23.2(2.4)$ & $22.1(2.8)$ \\
$34.6(3.8)$ & $41.6(5.3)$ & $47.9(4.0)$ & $9.3(1.9)$ & $26.2(1.9)$ & $19.0(2.7)$ \\
$24.6(2.5)$ & $30.6(2.9)$ & $40.9(3.5)$ & $11.0(0.8)$ & $22.8(3.6)$ & $16.9(2.0)$ \\
$24.6(2.5)$ & $28.8(2.4)$ & $33.9(3.0)$ & $9.4(1.3)$ & $15.0(1.4)$ & $9.8(1.5)$ \\
$28.5(2.5)$ & $24.6(2.2)$ & $40.6(4.8)$ & $11.5(2.7)$ & $13.2(1.1)$ & $12.7(2.2)$ \\
$35.6(4.2)$ & $36.0(2.4)$ & $53.6(5.1)$ & $16.8(2.7)$ & $23.3(1.7)$ & $20.3(3.6)$ \\
$64.4(1.9)$ & $64.3(4.0)$ & $85.3(8.1)$ & $25.6(2.4)$ & $36.2(3.4)$ & $34.7(3.4)$ \\
$47.8(3.4)$ & $50.9(3.2)$ & $53.8(5.7)$ & $22.7(3.0)$ & $26.6(3.7)$ & $19.9(2.6)$ \\
$54.9(3.9)$ & $58.5(2.7)$ & $86.2(5.7)$ & $21.4(0.8)$ & $40.9(2.8)$ & $24.7(2.0)$
\end{tabular}

$1 / 1 / \mathbf{I}$

$1 / 2 / \mathbf{I}$

$46.0(2.9)$

$56.9(8.1)$

$14.0(2.5)$

$23.2(2.4)$

$22.1(2.8)$

$1 / 3 /$ III

$30.6(2.9)$

$2 / 1 / \mathrm{I}$

$28.8(2.4)$

2/2/III

2/3/II

$35.6(4.2)$

$64.3(4.0)$

$3 / 1 /$ III

$54.9(3.9)$

$58.5(2.7)$

$86.2(5.7)$

$21.4(0.8)$

$40.9(2.8)$

"Exp" in column 1 refers to three different immunogold labeling experiments; results on control sections from the different experiments are given in Table 1. Abbreviations in columns 2-6: CTT, cervicothalamic tract terminals $(n=$ 8 ); RL, round large terminals $(n=8)$; RS, round small terminals $(n=8)$; PSD, presynaptic dendrites $(n=8)$; CB, large neuronal cell bodies $\left(n=4\right.$; one micrograph covering about $10 \mu \mathrm{m}^{2}$ of the cytoplasm in each neuron was analyzed). Tissue average refers to gold particle density over random electron micrographs $\left(n-8\right.$; each covering about $\left.10 \mu \mathrm{m}^{2}\right)$. Values within parentheses represent SEM. Note that the general labeling density of the different sections varies and that comparisons can thus only be made horizontally, that is, between structures within the same section. 


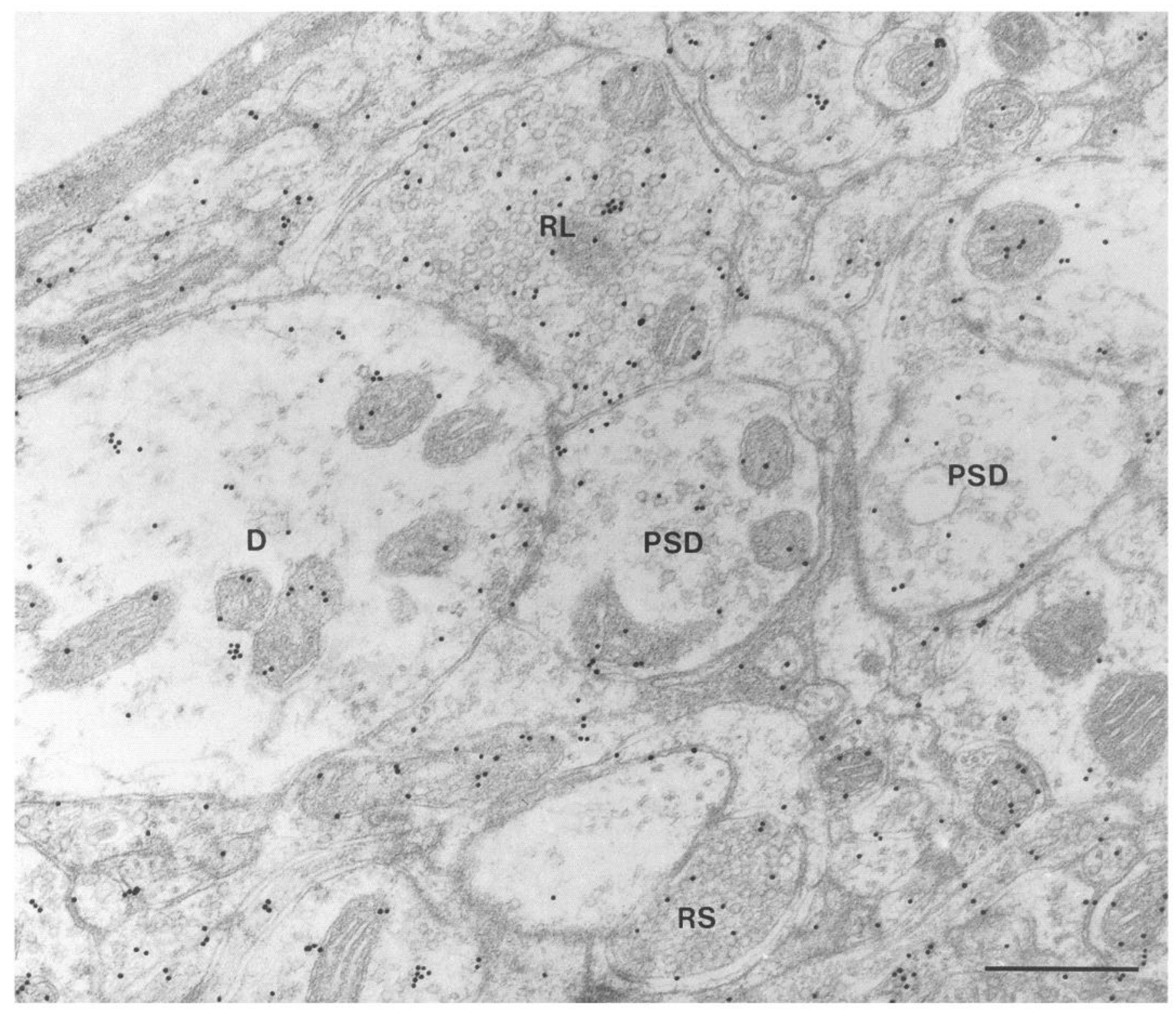

Figure 6. EM overview of the VPL neuropil from a Glu immunogold-stained section. Note the widespread but differentiated labeling with gold particles. $R L$, round large terminal; $R S$, round small terminal; $P S D$, presynaptic dendrite; $D$, dendrite. Scale bar, $0.5 \mu \mathrm{m}$.

particles, as well as that over RS terminals, PSDs, and large neuronal cell bodies, was significantly different from that over CTT terminals in all cats. In cat 1 , but not in the other two, there was a significant difference between the density of gold particles over CTT terminals and RL terminals.

When the normalized values from all sections in all animals are compared (Fig. 9B), the distribution for the different profile types, with the exception of RL terminals, is different from that of the CTT terminals. The density of gold particles over CTT terminals was significantly different from that over the other profile types, with the exception of that over RL terminals.

The results of the quantitative evaluation of gold particle density over graded sections containing conjugates with different concentrations of fixed Glu are shown in Figure 10. The results were similar in all sections, showing increasing values of gold particle density with increasing concentrations of fixed Glu. The relationship did not, however, appear to be entirely linear, in that the values for gold particle density tended to level off slightly at higher concentrations of fixed Glu. The shape of the curve is probably sensitive to even small differences in incubation parameters inasmuch as it has shown some variation among different studies (cf. Bramham et al., 1990; Ottersen et al., 1991).

The conjugates from which the relation between concentration of fixed Glu and the density of gold particles was calculated were prepared without addition of $\mathrm{OsO}_{4}$. Also included in the sections is an $\mathrm{OsO}_{4}$-treated conjugate containing the same Glu concentration as the nontreated conjugate with the highest concentration of Glu ( $32 \mathrm{~mm}$ ). The labeling over the $\mathrm{OsO}_{4}$-treated conjugates was about $65 \%$ of that over the nontreated conjugates, indicating a residual masking effect of $\mathrm{OsO}_{4}$. Therefore, the curves in Figure $10 \mathrm{~A}$ cannot be used for estimating the absolute values of Glu content in the different VPL tissue struc- 

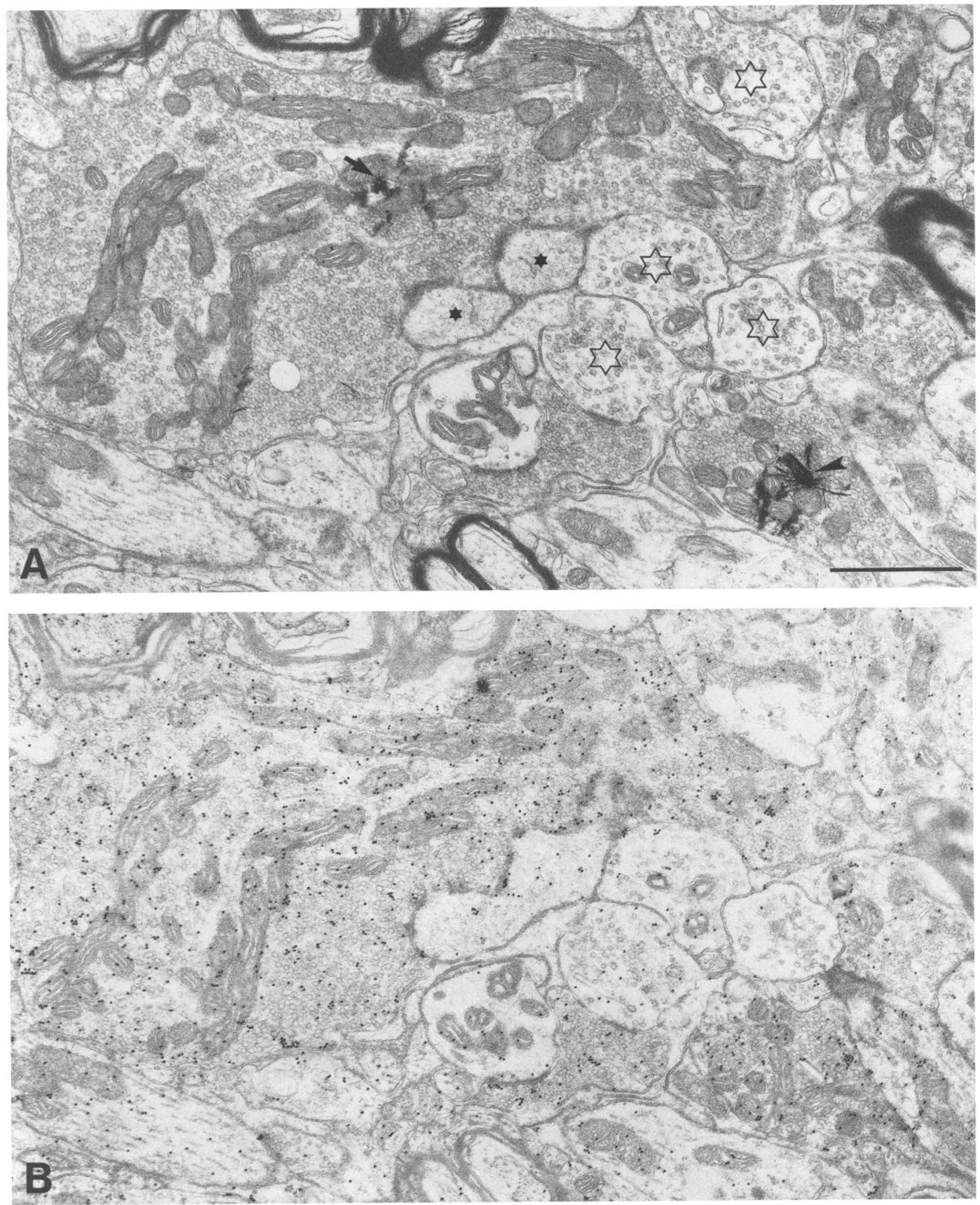

Figure 7. A pair of electron micrographs showing the corresponding area in two adjacent ultrathin sections. In $A$, a non-immunogold-labeled section, two peroxidase-labeled CTT terminals are seen. The larger, lightly peroxidase-labeled (arrow) terminal is in synaptic contact with two dendritic appendages (solid stars) that are seen to fuse in $B$. The smaller terminal contains more dense TMB reaction product (arrowhead). In $B$, an adjacent section labeled with Glu antiserum, high densities of gold particles are seen over the CTT terminals as compared to PSDs (open stars in $A$ ) and other tissue components. Scale bar, $0.5 \mu \mathrm{m}$ (valid for $A$ and $B$ ). 

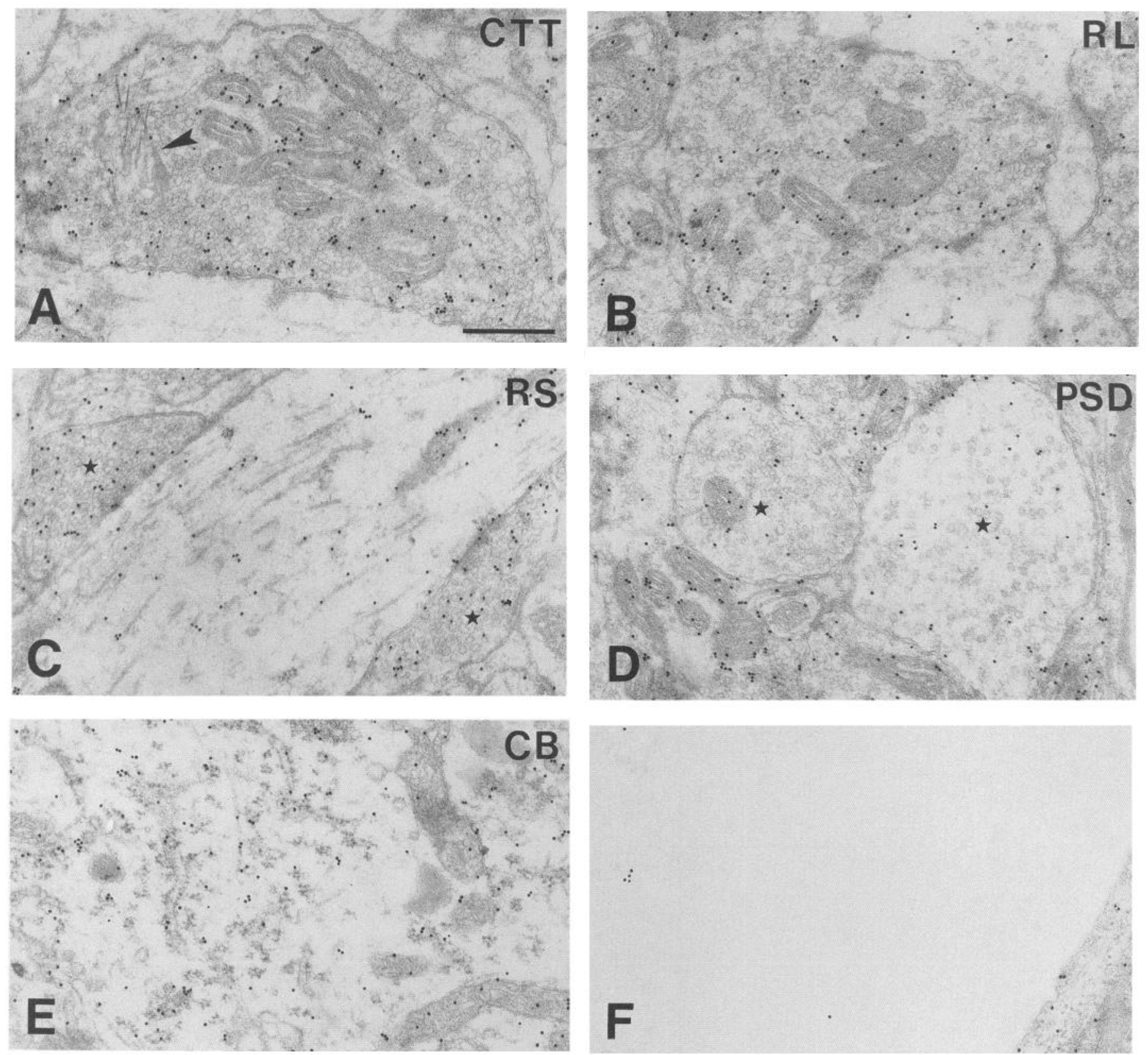

Figure 8. A series of electron micrographs from a Glu immunogold-labeled section showing examples of gold labeling density over different profile types in the VPL. Profile type is indicated at the upper right of each micrograph ( $F$ shows part of the lumen of a blood vessel; note low density of gold particles over empty resin). Faded TMB reaction product (due to treatment of the section with $\mathrm{NaIO}_{4}$ ) is seen in the CTT terminal (arrowhead in $A$ ). Two profiles of each type, indicated by stars, are seen in $C$ and $D$. A high density of gold particles is seen over CTT, RL, and RS terminals, whereas PSDs are only lightly labeled. The neuronal cell body $(C B)$ in $E$ has a density of gold particles intermediate to that seen over the terminals and the PSDs. Scale bar, $0.5 \mu \mathrm{m}$ (valid for $A-F$ ).

tures (also note that the graded sections, as opposed to the VPL sections, were labeled on both sides).

\section{Discussion}

In the present study, we have combined anterograde transport of WGA-HRP and quantitative analysis of EM immunogold labeling to investigate the presence of Glu-LI in terminals of the CTT in the VPL. The results show that the CTT terminals are enriched in Glu-LI. Enrichment of Glu-LI was also found in non-peroxidase-labeled terminals with the same morphologic characteristics as the CTT terminals (RL terminals), and in RS terminals whose appearance corresponds to terminals of cortical origin. The latter type of terminals contained the highest level of Glu-LI. PSDs contained low levels of Glu-LI, while large neuronal cell bodies in the VPL were moderately stained by gold particles. These findings are of importance with regard to the identification of neurotransmitters in the VPL, but before discussing the results in this context, some considerations regarding technical issues will be made.

\section{Methodological considerations}

One issue that could interfere with the object of the study would be the presence of transneuronal transport of the tracer, leading to peroxidase labeling of structures other than CTT terminals 
CervicoThalamic Tract terminals

Round Large terminals

Round Small terminals

Presynaptic Dendrites

Large neuronal cell bodies

Average tissue level

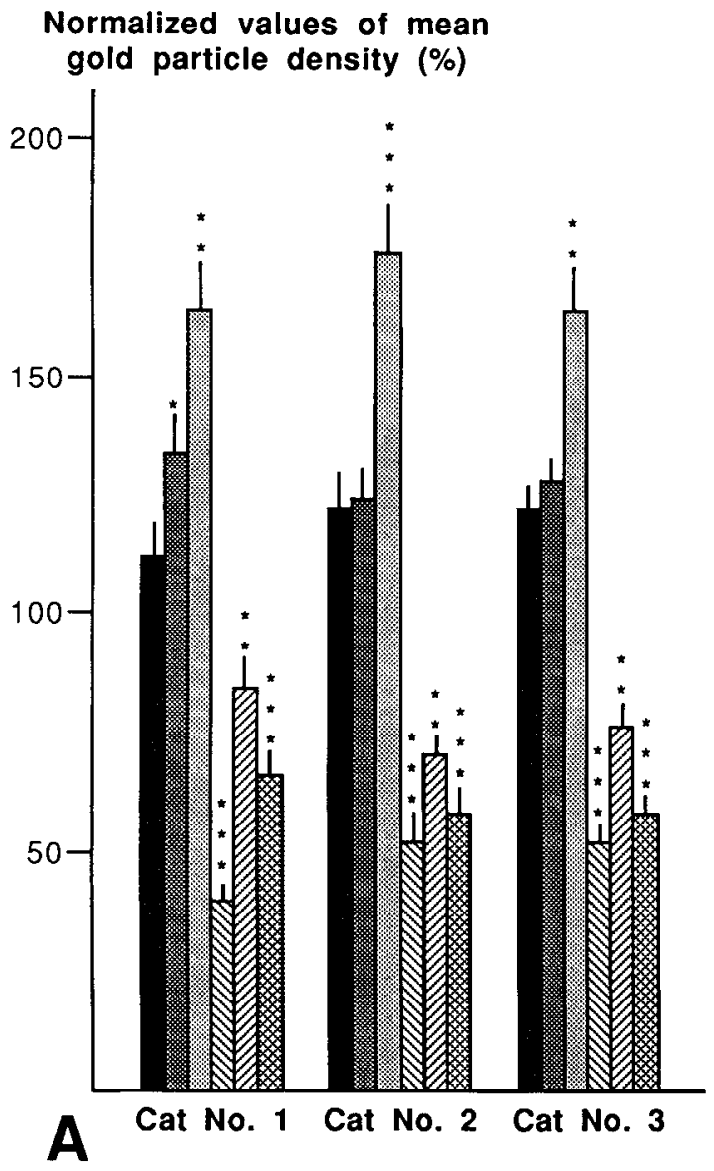

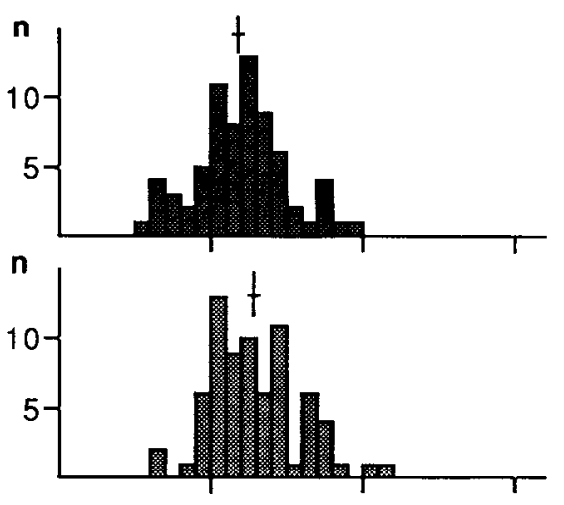
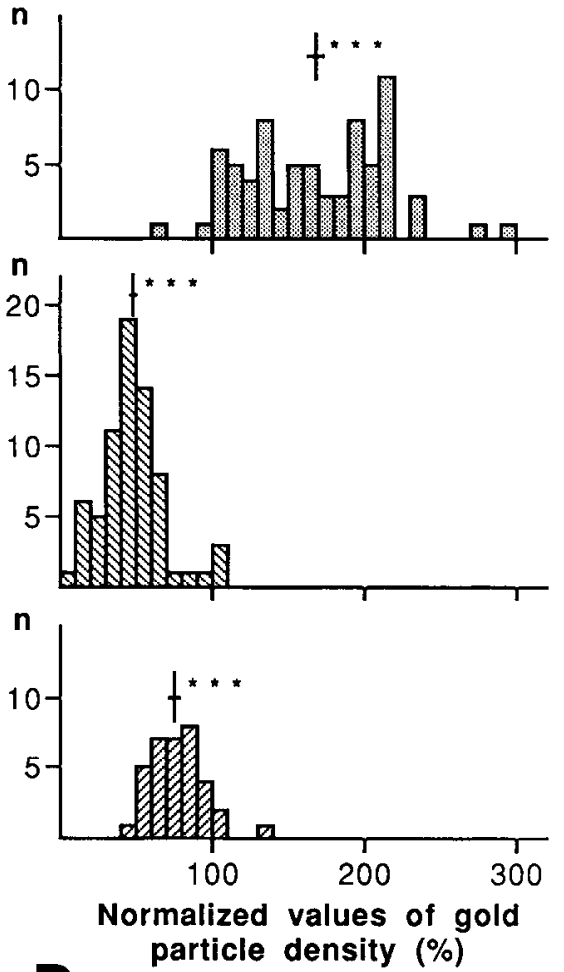

Figure 9. Histograms presenting the distribution of normalized values of gold particle density over different neuronal structures in the VPL. To allow a direct comparison between the gold labeling density over different sections (different sections had varying general density of gold particles; see Table 2), actual values for gold particle density were normalized as follows: (1) for each section, the mean gold particle density $(M)$ for all analyzed structures (including random electron micrographs) was calculated and set to $100 \%$ by multiplying the mean value with a factor $A(M \times$ $A=100 \%$ ); (2) the factor $A$ was calculated for each section by dividing $100 \%$ with the mean gold particle density for the section $(A=100 \% / M)$; (3) the density of gold particles for each structure was then normalized by multiplying the actual value of gold particle density with $A$ (actual density of gold particles $\times A=$ normalized gold particle density). Thus, the value for normalized gold particle density for a particular structure expresses the labeling density as a percentage of the mean density for all structures analyzed in the section. In $A$, the normalized mean gold particle densities for different structures in the three cats are shown. Error bars indicate SEM, and asterisks indicate significantly different labeling density in comparison with the labeling density of CTT terminals (Wilcoxon's signed rank test performed on primary values, i.e., values not subjected to normalization; ${ }^{*}, p<0.05 ;{ }^{* *}, p<0.01 ;{ }^{* * *}, p$ $<0.001)$. The histograms in $B$ show the normalized gold particle density for all structures in all sections. Vertical bars above histograms indicate mean values, and the horizontal bars indicate \pm SEM. Statistical comparison was performed as in $A$.
(Itoh et al., 1984; Peschanski and Ralston, 1985). In the present material, peroxidase labeling was, with the exception of axons, seen only in terminals having the morphologic characteristics previously assigned to CTT terminals (Blomqvist et al., 1985b). The TMB reaction product could occasionally be seen penetrating through the membrane into the extracellular space or, more rarely, into adjacent structures, but was never found isolated in other types of structures. These observations suggest that detectable levels of transneuronal transport have not occurred, and it is therefore likely that all peroxidase-positive profiles are terminals of ascending afferents from neurons located within the injection sites in the spinal cord.

As the injection sites were not restricted to the $\mathrm{LCN}$, the possibility should be considered that some of the HRP-labeled terminals in the VPL were derived from STT cells in areas adjacent to the LCN. In one of the cats, terminal labeling was present in the Sm. Previous studies have not found any projection to Sm from the LCN (Boivie, 1970; Berkley, 1980), and no termination was noted in the other cats, in which the injections showed lesser involvement of the dorsal horn. It therefore appears most likely that the terminal labeling in $\mathrm{Sm}$ originates from lamina I cells in the dorsal horn (Craig and Burton, 1981). Although labeling of STT terminals is likely to have occurred in at least one of the cats, it appears unlikely that the present sample of peroxidase-positive terminals should be contaminated with terminals from the STT. As the injection sites all were centered in or close to the I.CN, the CTT should be the cause of at least a substantial proportion of the terminal labeling in the thalamus. The termination pattern in the thalamus in the present material is also closely similar to that observed in previous studies of the CTT (Boivie, 1970; Berkley, 1980; Blomqvist et al., 1985b), and is clearly different from the termination of the STT (Craig and Burton, 1985). Whereas the core of the VPL, from which the present sample of terminals was gathered, receives a strong input from the LCN, STT termination in this area is very sparse in cats. Although the details are unclear regarding the termination pattern of STT fibers originating from segments $\mathrm{Cl}$ and $\mathrm{C} 2$, Carstens and Trevino (1978) found numerous labeled neurons in the DCN and LCN after injections of HRP limited to the VPL, but no neurons in the gray substance 

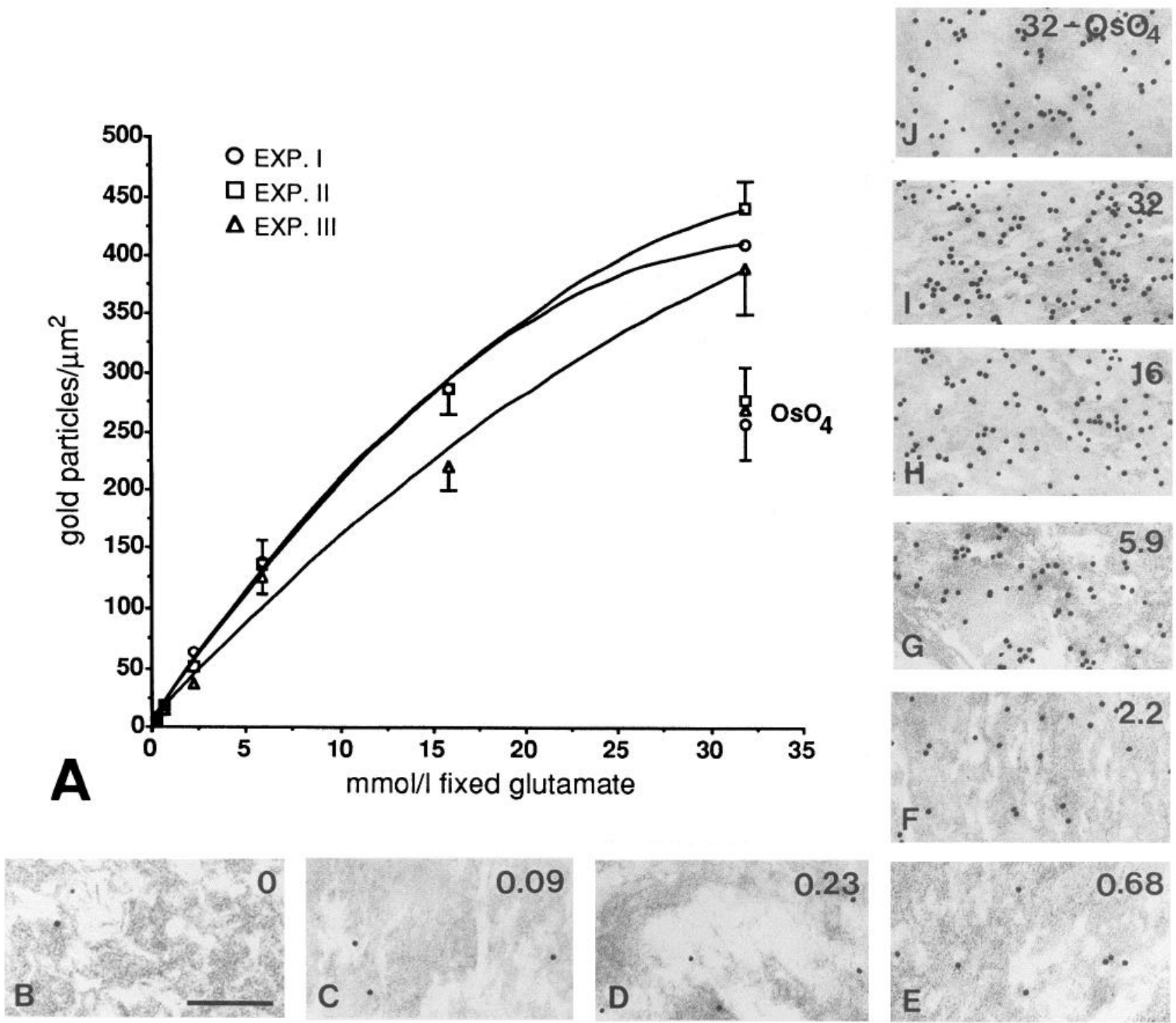

Figure 10. Quantitative evaluation of gold particle density over conjugates with different concentrations of Glu in graded sections (for preparation of graded sections, see Ottersen, 1989b; Bramham et al., 1990). A, Diagram showing the relation between gold particle density and concentration of fixed Glu in the three graded sections included in the present Glu immunogold labeling experiments. The curves were drawn by a computer and represent polynomial regression of the second order. Bars indicate SEM (for some values, bars have been excluded for reasons of space). The curves correlate to values obtained over conjugates not treated with $\mathrm{OsO}_{4}$. The lower values over the $\mathrm{OsO}_{4}$-treated conjugates containing 32 mM $\mathrm{Glu}$ indicate that a masking effect of $\mathrm{OsO}_{4}$ was present in the experiments. The diagram should therefore not be used for calculating absolute values of Glu in the different tissue structures. $B-J$ show examples of gold particle density over different conjugates in one of the sections $(E X P . I)$. Concentration of fixed Glu (mmol/liter) is given at the upper right of each micrograph. Scale bar, $0.25 \mu \mathrm{m}$ (valid for $B-J$ ).

adjacent to the LCN. This observation suggests that at least in this respect, the contralateral projection of the STT from C1 and $\mathrm{C} 2$ is similar to that from other levels of the spinal cord. In conclusion, it appears likely that most, if not all, of the peroxidase-positive terminals sampled in the present study originate from neurons in the $\mathrm{LCN}$.

A third question is whether the peroxidase labeling may have interfered with the immunogold labeling by decreasing the density of gold particles over terminals containing TMB reaction product. One way to evaluate this would be to compare the density of gold particles over CTT terminals and RL terminals. The latter terminals most probably originate from ascending afferents, either from the DCN or from the LCN (Blomqvist et al., 1985b; Ralston, 1985) (terminals from the LCN may have failed to be labeled for technical reasons or may not contain TMB reaction product in the plane of the section). An origin from STT cells is also possible but appears less likely for reasons given above. Terminals in the VPL originating from the DCN and LCN have the same appearance and synaptic organization and are thus indistinguishable by morphological criteria only (Blomqvist et al., 1985b). The validity in comparing gold particle density over CTT and RL terminals would be dependent on their also being similar with regard to content of Glu. With the assumption that this is the case, the present observations suggest that the peroxidase labeling may decrease the gold labeling, but only to a minor degree. In one of the cats, the density 
of gold particles was significantly lower over CTT terminals by about $15 \%$, while in the other cats no significant difference between CTT and RL terminals was evident. The small effects of peroxidase labeling on the density of gold particles suggested by these observations would not interfere with the general conclusions regarding the distribution of Glu between different tissue components in the VPL.

The immunogold labeling pattern for Glu seen in the present and previous studies (e.g., Somogyi et al., 1986; Ottersen, 1987, 1989a,b; Montero and Wenthold, 1989; Broman et al., 1990; Maxwell et al., 1990; Montero, 1990; Ji et al., 1991) is much less differentiated than that seen, for example, with GABA (Somogyi and Hodgson, 1985; De Biasi et al., 1988; Ottersen, 1989a). Specifically at sites where the gold particle density is low, such as over astrocytes and PSDs, it is important to evaluate whether the low density of gold particles represents unspecific binding to resin or cross-reacting substances in the tissue or if it represents low levels of fixed Glu. Several observations support the latter explanation. The antiserum reacts strongly with fixed Glu, as shown by the control sections. The immunogold labeling seen over the graded sections also shows that the method is able to recognize even low concentrations of Glu $(<0.1$ mm; see also Bramham et al., 1990). Only low densities of gold particles were found over empty resin, and the resin labeling was also subtracted from the different values of tissue labeling. In the control sections, the density of gold particles over the None conjugates, which represent highly condensed brain macromolecules fixed with glutaraldehyde, was less than the average tissue labeling in the VPL, although the control sections as opposed to tissue sections were labeled on both sides. It has also been found that the antigen recognized by the Glu antiserum used in the present study represents a substance that is easily redistributed in the tissue during conditions known to induce transmitter release (high $\left[\mathrm{K}^{+}\right]$; Ottersen et al., 1990a,b), indicating that the antiserum recognizes a releasable substance and not structural components of the tissue (cf. McDonald et al., 1989). Altogether, the observations referred to above strongly support the hypothesis that the labeling obtained with the immunogold procedure used in the present study shows the presence of a Glu-like substance, and most probably Glu itself. Besides being a neurotransmitter, Glu also subserves metabolic functions in intermediary metabolism and in protein synthesis as well as acting as a precursor of GABA (Fonnum, 1984). In light of previous and present observations, it is reasonable to conclude that the scattered, low-density gold labeling represents the ubiquitous presence of Glu in most or all tissue compartments.

In order to evaluate the present findings, it would be helpful to know the relationship between the density of gold particles and the concentration of fixed Glu. The graded sections incubated with the tissue sections in the present experiments showed, as would be expected, increasing values of gold particle density with increasing concentrations of fixed Glu. However, a masking effect of $\mathrm{OsO}_{4}$ was found to be present, which precludes a direct comparison of the labeling density over the conjugates and the tissue sections. As the general labeling density varied between the tissue sections, it would be unreliable to try to extrapolate absolute concentrations of fixcd Glu in the tissue compartments from the gold particle density over the $\mathrm{OsO}_{4}$-treated conjugate. Such a comparison will therefore not be made. However, the shape of the curves in Figure $10 \mathrm{~A}$ provides information that is of importance for the interpretation of the immunogold labeling in the VPL. According to these curves, there is an almost direct relationship between gold particle density and antigen concentration. This implies that the difference in labeling intensity between two profiles (expressed as the ratio between the respective particle densities) should reflect closely the ratio between their molar concentrations of fixed Glu. However, since the curves show a tendency to level off at high antigen concentrations, it is likely that the present particle density values slightly underestimate the difference in concentration of fixed Glu between the structures with high (CTT, RL, and RS terminals) and those with lower (PSDs, neuronal cell bodies, and average tissue level) density of gold particles.

\section{General comments on glutamate immunohistochemistry}

There is still no ideal method available for identifying glutamatergic pathways in the brain. A multitude of biochemical, physiologic, and morphologic methods have been used, but each of them has its specific set of potentials and limitations (Ottersen, 1991). Immunohistochemical methods have during recent years been of enormous value for detailed studies of the distribution of neuroactive substances like monoamines, peptides, and GABA in the CNS. However, although antiserum against fixed Glu has been available for several years (Storm-Mathisen et al., 1983), the functions of Glu both as a neurotransmitter and as a metabolic amino acid have made the use of immunohistochcmistry for delineating glutamatergic pathways more difficult. By use of biochemical methods, it has been estimated that the metabolic pool actually accounts for the major proportion of Glu in the brain (Fonnum, 1984), and Glu antisera cannot differentiate between the transmitter and metabolic pools. Cell body labeling as a marker of transmitter identity has been useful in the case of many neuroactive substances, but is of doubtful value in the case of Glu. The level of Glu-LI in neuronal cell bodies is likely to reflect more closely the size of the metabolic pool, and there is also evidence that Glu antisera may label neurons thought to use other neurotransmitters (Ottersen and Storm-Mathisen, 1984; Storm-Mathisen and Ottersen, 1988). It is likely that more reliable information about transmitter identity could be gained by instead focusing the immunohistochemical analysis on the nerve terminals. However, by conventional light microscopic immunohistochemistry this has also proven to be difficult (Ottersen and Storm-Mathisen, 1984; Storm-Mathison and Ottersen, 1988; but see C.-j. Liu et al., 1989).

As a means to overcome this problem, EM postembedding labeling with colloidal gold particles, which makes a quantitative analysis possible, has been developed (Somogyi and Hodgson, 1985; Somogyi et al., 1986; Ottersen, 1987, 1989a,b). Quantitative evaluation of immunogold labeling has previously been used for studying the distribution of Glu-LI foremost in the hippocampal formation and in the cerebellum (Somogyi et al., 1986; Ottersen, 1989a,b; Bramham et al., 1990; Ottersen et al., 1990a,b; Zhang et al., 1990). These parts of the brain contain well-defined nerve terminal populations that, on the basis of studies with other techniques, are thought to use Glu or another excitatory amino acid as neurotransmitter. These immunogold studies have invariably shown that putative glutamatergic terminals are enriched in Glu-LI, whereas putative GABAergic terminals contain only low levels of Glu-LI. It therefore appears reasonable to assume that enrichment of Glu-LI is a feature common to glutamatergic terminals. Whether the opposite is true, that terminals not releasing Glu invariably contain low 
levels of Glu-LI, is not known with certainty. It is reasonable to conclude that high levels of Glu-LI in a nerve terminal population strongly support Glu as a neurotransmitter in such terminals, but enrichment of Glu-LI should not by itself be regarded as a definite marker for glutamatergic terminals. Glu immunogold findings should be evaluated in conjunction with data from studies employing other techniques to investigate excitatory amino acid neurotransmission.

\section{Glutamate as a putative neurotransmitter in the VPL}

A role for Glu as a neurotransmitter in the VPL is supported by the finding that Glu or other excitatory amino acid receptor agonists excite VPL neurons (Curtis et al., 1972; Haldeman et al., 1972; Salt, 1986, 1988). Autoradiographic studies have also revealed the presence of Glu binding sites in the VPL (Greenamyre et al., 1984; Halpain et al., 1984).

The nerve terminals found to contain the highest levels of Glu-LI in the present study were the RS terminals. The appearance of these corresponds to that of terminals originating from neurons in layer VI of the somatosensory cortex, and it appears likely that at least a major proportion of the sampled terminals are of cortical origin. It is possible, however, that somc of the RS terminals are derived from other, yet unidentified sources (Jones, 1985; Ralston, 1985). Previous studies with several different techniques, including biochemical methods and retrograde tracing with $\mathrm{D}^{3}{ }^{3} \mathrm{H}$-aspartate, have provided strong evidence for Glu as a neurotransmitter in the corticothalamic projection to the VPL and other thalamic nuclei (for references and review of previous findings, see Jones, 1985; Rustioni and Weinberg, 1989), and the present findings provide further support for Glu as a corticofugal neurotransmitter.

As would be expected, only low levels of Glu-LI were detected in PSDs. These vesicle-containing dendrites and dendritic appendages originate from VPL local circuit neurons, whose GABAergic nature is well established (Rustioni and Weinberg, 1989). Also, in studies with Glu immunogold labeling in the hippocampus and the cerebellum, low levels of Glu-LI have been detected in putative GABAergic terminals (Somogyi ct al., 1986; Ottersen, 1989a,b; Bramham et al., 1990; Ottersen et al., 1990a,b; Zhang et al., 1990). It appears likely that the glutamic acid decarboxylase (GAD) present in such structures will keep the levels of Glu low by transforming Glu into GABA.

The density of gold particles over large VPL neuronal cell bodies in Glu immunogold-labeled sections was intermediate to that of the other structure types analyzed. It was higher than the tissue average and higher than that over PSDs, but lower than that found over CTT, RL, and RS terminals. Probably, most of the neurons selected for analysis are thalamocortical projection neurons, as GABAergic local circuit neurons in the VPL generally are smaller than the neurons analyzed in the present study (Penny et al., 1983; Spreafico et al., 1983). GluLI has also previously been detected in GAD-negative VPL neurons in the cat by preembedding immunohistochemistry (Rustioni et al., 1988). However, the significance of the present and previous findings regarding Glu-LI in VPL neurons is, for reasons given above, of uncertain value for transmitter identification.

Concerning ascending somatosensory afferents to the VPL, it has been found that injections of $\mathrm{D}^{-3} \mathrm{H}$-aspartate into the thalamus label neurons in the somatosensory cortex but not in the DCN or the trigeminal complex (Rustioni et al., 1983). This finding may seem to argue against a role for excitatory amino acids in the synaptic transmission between ascending somatosensory afferents and VPL neurons. Negative findings with this technique do not, however, rule out a transmitter role for Glu or other excitatory amino acids, as the sensitivity for detection may vary between different putative glutamatergic pathways (for reviews, see Storm-Mathisen and Ottersen, 1988; Ottersen, 1991). Electrophysiologic-pharmacologic studies in rats have recently provided increasing evidence for an involvement of excitatory amino acids in the synaptic transmission between ascending somatosensory afferents and neurons in the thalamic ventrobasal complex (Salt, 1986, 1988; Klockgether, 1987), and the response to somatosensory stimulation in the ventrobasal complex seems to involve both NMDA and non-NMDA receptors (Salt and Eaton, 1989, 1991). The present findings that Glu-LI is enriched both in peroxidase-positive CTT terminals and non-peroxidase-labeled RL terminals further support the existence of excitatory amino acid neurotransmission between these afferents and VPL neurons and strongly suggest that Glu is an endogenous agonist for the receptors. Findings by Henderson and Salt (1988) in the rat indicate that $N$-acetylaspartylglutamate is unlikely to be a neurotransmitter of somatosensory afferents to the ventrobasal complex.

Yet another observation that may support a transmitter role for Glu in CTT terminals is the present finding that such terminals contain only very low levels of Gln-LI, lower than that found in astrocytes and lower than the average tissue level in the VPL. Further, when the ratios for Glu-LI:Gln-LI are compared, the difference between CTT terminals and astrocytes is even more compelling. One of the routes through which transmitter Glu may be formed is through deamidation of Gln (Fonnum, 1984; McGeer and McGeer, 1989), and it appears reasonable that high Glu:Gln ratios should be present in terminals that release and have a high turnover rate of Glu. Indeed, in recent studies on the cerebellar cortex (Ottersen et al., 1991; Zhang et al., 1991), high Glu:Gln ratios were found in parallel and mossy fiber terminals whereas in comparison to these terminals the ratios in other tissue compartments were low or moderate. Concerning Gln-LI in the VPL, it would be helpful to have more complete immunogold data on types of structures other than those given in the present report before further conclusions are made. Such work is now in progress.

In the present study, RS terminals were found to contain higher levels of Glu-LI than CTT and RL terminals. Similar differences have previously been found between retinal and cortical terminals in the macaque and cat LGN (Montero and Wenthold, 1989; Montero, 1990). Also, in the cerebellum and hippocampus, differences in content of Glu-LI between putative glutamatergic terminals have been observed (Somogyi et al., 1986; Bramham et al., 1990). The explanation for different concentrations of Glu in glutamatergic terminals is not clear. In Glu immunogold-labeled preparations, a relationship between the density of gold particles and the packing density of synaptic vesicles has been observed in individual terminals or among terminals of the same type (Montero and Wenthold, 1989; Ottersen et al., 1990b; Ji et al., 1991). The higher packing density of vesicles in RS terminals as compared to CTT and RL terminals (Blomqvist et al., 1985b) could thus explain the higher content of Glu-LI in RS terminals. However, in the hippocampus it has recently been found that terminals with asymmetric synaptic junctions in the outer zone of the dentate molecular layer contain higher levels of Glu-LI than mossy fiber terminals, although the latter have a higher density of synaptic vesicles 
(Bramham et al., 1990). These findings could reflect differences in vesicular content of Glu between different glutamatergic terminal populations. Whether the difference in content of Glu-LI between RS terminals and CTT and RL terminals is dependent on differences in density of synaptic vesicles, possible differences in vesicular content of Glu, or a combination of both, cannot be established by the present data.

Although the present findings strongly support Glu as a neurotransmitter in CTT and RL terminals, they do not imply that Glu is the only substance that may be released from such terminals. During recent years, numerous studies in different species have described the presence of various peptides in neuronal cell bodies projecting to the thalamus, or in terminals in the thalamus thought to originate from neurons in different somatosensory relays (Hunt et al., 1987; Ju et al., 1987; Battaglia et al., 1988; Leah et al., 1988; Nahin, 1988; Rustioni et al., 1988; Hirai and Jones, 1989; X.-B. Liu et al., 1989). At present, nothing is known about the possible presence of peptides in CTT neurons and terminals, and further studies are necessary to establish whether Glu is colocalized with other releasable substances in CTT terminals.

In conclusion, the present data provide anatomical evidencc that supports a neurotransmitter role for Glu in terminals of the CTT and other ascending somatosensory pathways to the VPL. We have previously found that spinocervical tract terminals in the LCN are also enriched in Glu-LI (Broman et al., 1990). It therefore appears likely that synaptic transmission in the SCTP is dependent on the release of Glu both at the level of the LCN and the VPL.

\section{References}

Battaglia G, Spreafico R, Rustioni A (1988) Substance P-immunoreactive fibers in the thalamus from ascending somatosensory pathways. In: Cellular thalamic mechanisms (Bentivoglio M, Spreafico R, eds), pp 365-374. Amsterdam: Elsevier.

Benveniste H, Drejer J, Schousboe A, Diemer NH (1984) Elevation of the extracellular concentrations of glutamate and aspartate in rat hippocampus during transient cerebral ischemia monitored by intracerebral microdialysis. J Neurochem 43:1369-1374.

Berkley KJ (1980) Spatial relationships between the terminations of somatic sensory and motor pathways in the rostral brainstem of cats and monkeys. I. Ascending somatic sensory inputs to lateral diencephalon. J Comp Neurol 193:283-317.

Blackstad TW, Karagülle T, Ottersen OP (1990) Morforel, a computer program for two-dimensional analysis of micrographs of biological specimens, with emphasis on immunogold preparations. Comput Biol Med 20:15-34.

Blomqvist A, Westman J, Köhler C, Wu J-Y (1985a) Immunocytochemical localization of glutamic acid decarboxylase and substance $P$ in the lateral cervical nucleus: a light and electron microscopic study in the cat. Neurosci Lett 56:229-233.

Blomqvist A, Flink R, Westman J, Wiberg M (1985b) Synaptic terminals in the ventroposterolateral nucleus of the thalamus from neurones in the dorsal column and lateral cervical nuclei: an electron microscopic study in the cat. J Neurocytol 14:869-886.

Boivie J (1970) The termination of the cervicothalamic tract in the cat. An experimental study with silver impregnation methods. Brain Res 19:333-360.

Boivie J (1980) Thalamic projections from lateral cervical nucleus in monkey. A degeneration study. Brain Res 198:13-26.

Bovic J (1983) Anatomic and physiologic features of the spino-cervicothalamic pathway. In: Somatosensory integration in the thalamus (Macchi G, Rustioni A, Spreafico R, eds), pp 63-106. Amsterdam: Elsevier.

Bramham CR, Torp R, Zhang N, Storm-Mathisen J, Ottersen OP (1990) Distribution of glutamate-like immunoreactivity in excitatory hippocampal pathways: a semiquantitative electron microscopic study in rats. Neuroscience 39:405-417.
Broman J, Blomqvist A (1989a) GABA-immunoreactive neurons and terminals in the lateral cervical nucleus of the cynomolgus monkey. J Comp Neurol 283:41 5-424.

Broman J, Blomqvist A (1989b) Substance P-like immunoreactivity in the lateral cervical nucleus of the owl monkey (Aotus trivirgatus): a comparison with the cat and rat. J Comp Neurol 289:111-117.

Broman J, Blomqvist A (1990) Serotonergic innervation of the lateral cervical nucleus: an immunohistochemical study in cats and monkeys (Aotus trivirgatus). Synapse 6:55-62.

Broman J, Westman J (1988) GABA-immunoreactive neurons and terminals in the lateral cervical nucleus of the cat. J Comp Neurol 274:467-482.

Broman J, Westman J, Ottersen OP (1990) Ascending afferents to the lateral cervical nucleus are enriched in glutamate-like immunoreactivity: a combined anterograde transport-immunogold study in the cat. Brain Res 520:178-191.

Burton H, Craig AD (1983) Spinothalamic projections in cat, raccoon and monkey: a study based on anterograde transport of horseradish peroxidase. In: Somatosensory integration in the thalamus (Macchi G, Rustioni A, Spreafico R, eds), pp 17-41. Amsterdam: Elsevier.

Carstens E, Trevino DL (1978) Laminar origins of spinothalamic projections in the cat as determined by the retrograde transport of horseradish peroxidase. J Comp Neurol 182:151-166.

Craig AD Jr, Burton H (1981) Spinal and medullary lamina I projection to nucleus submedius in medial thalamus: a possible pain center. J Neurophysiol 45:443-466.

Craig AD, Burton $\mathrm{H}$ (1985) The distribution and topographical organization in the thalamus of anterogradely-transported horseradish peroxidase after spinal injections in cat and raccoon. Exp Brain Res 58:227-254.

Curtis DR, Duggan AW, Felix D, Johnston GAR, Tebecis AK, Watkins JC (1972) Excitation of mammalian central neurones by acidic amino acids. Brain Res 41:283-301.

De Biasi S, Rustioni A (1990) Ultrastructural immunocytochemical localization of excitatory amino acids in the somatosensory system. J Histochem Cytochem 38:1745-1754.

De Biasi S, Frassoni C, Spreafico R (1988) The intrinsic organization of the ventroposterolateral nucleus and related reticular thalamic nucleus of the rat: a double labeling ultrastructural investigation with $\gamma$-aminobutyric acid immunogold staining and lectin-conjugated horseradish peroxidase. Somatosens Res 5:187-203.

Fonnum F (1984) Glutamate: a neurotransmitter in mammalian brain. J Neurochem 42:1-11.

Giesler GJ Jr, Elde RP (1985) Immunocytochemical studies of the peptidergic content of fibers and terminals within the lateral spinal and lateral cervical nuclei. J Neurosci 5:1833-1841.

Greenamyre JT, Young AB, Penney JB (1984) Quantitative autoradiographic distribution of $\mathrm{L}-\left[{ }^{3} \mathrm{H}\right]$ glutamate-binding sites in rat central nervous system. J Neurosci 4:2133-2144.

Haldeman S, Huffman RD, Marshall KC, McLennan H (1972) The antagonism of the glutamate-induced and synaptic excitations of thalamic neurones. Brain Res 39:419-425.

Halpain S, Wieczorek CM, Rainbow TC (1984) Localization of L-glutamate receptors in rat brain by quantitative autoradiography. $\mathrm{J}$ Neurosci 4:2247-2258.

Hanker JS, Yates PE, Metz CB, Rustioni A (1977) A new specific, sensitive and non-carcinogenic reagent for the demonstration of horseradish peroxidase. Histochem J 9:789-792.

Henderson $Z$, Salt TE (1988) The effects of $N$-acetylaspartylglutamate and distribution of $N$-acetylaspartylglutamate-like immunoreactivity in the rat somatosensory thalamus. Neuroscience 25:899-906.

Henry MA, Westrum LE, Johnson LR (1985) Enhanced ultrastructural visualization of the horseradish peroxidase-tetramethylbenzidine reaction product. J Histochem Cytochem 33:1256-1259.

Hirai T, Jones EG (1989) Distribution of tachykinin- and enkephalinimmunoreactive fibers in the human thalamus. Brain Res Rev 14: $35-52$.

Hunt CA, Seroogy KB, Gall CM, Jones EG (1987) Cholecystokinin innervation of rat thalamus, including fibers to ventroposterolateral nucleus from dorsal column nuclei. Brain Res 426:257-269.

Itoh K, Yasui Y, Takada M, Mitani A, Kaneko T, Sugimoto T, Mizuno N (1984) An anterograde-retrograde transneuronal transport of conjugates of wheat germ agglutinin with horseradish peroxidase (WGAHRP): labeling of neurons in the reticular nucleus of the thalamus 
with WGA-HRP injected into the posterior column nuclei in the cat. Brain Res 323:185-187.

Ji Z, Aas J-E, Laake J, Walberg F, Ottersen OP (1991) An electron microscopic, immunogold analysis of glutamate and glutamine in terminals of rat spinocerebellar fibers. J Comp Neurol 307:296-310.

Jones EG (1985) The thalamus. New York: Plenum.

Ju G, Melander T, Ceccatelli S, Hökfelt T, Frey P (1987) Immunohistochemical evidence for a spinothalamic pathway co-containing cholecystokinin- and galanin-like immunoreactivities in the rat. Neuroscience 20:439-456.

Klockgether T (1987) Excitatory amino acid receptor-mediated transmission of somatosensory evoked potentials in the rat thalamus. $J$ Physiol (Lond) 394:445-461.

Laake JH, Gundersen V, Nordbø G, Ottersen OP, Storm-Mathisen J (1986) An antiserum against glutamine. In: Excitatory amino acids (Roberts PJ, Storm-Mathisen J, Bradford HF, eds), pp 448-450. London: Macmillan.

Leah J, Menétrey D, de Pommery J (1988) Neuropeptides in long ascending spinal tract cells in the rat: evidence for parallel processing of ascending information. Neuroscience 24:195-207.

Liu C-j, Grandes P, Matute C, Cuénod M, Streit P (1989) Glutamatelike immunoreactivity revealed in rat olfactory bulb, hippocampus and ccrebellum by monoclonal antibody and sensitive staining method. Histochemistry 90:427-445.

Liu X-B, Jones EG, Huntley GW, Molinari M (1989) Tachykinin immunoreactivity in terminals of trigeminal afferent fibers in adult and fetal monkey thalamus. Exp Brain Res 78:479-488.

Mantyh PW (1983) The spinothalamic tract in the primate: a reexamination using wheatgerm agglutinin conjugated to horseradish peroxidase. Neuroscience 9:847-862.

Maxwell D., Christie WM, Somogyi P (1989) Synaptic connections of GABA-containing boutons in the lateral cervical nucleus of the cat: an ultrastructural study employing pre- and post-embedding immunocytochemical methods. Neuroscience 33:169-184.

Maxwell DJ, Christie WM, Short AD, Storm-Mathisen J, Ottersen OP (1990) Central boutons of glomeruli in the spinal cord of the cat are enriched with L-glutamate-like immunoreactivity. Neuroscience 36 : 83-104.

McDonald AJ, Beitz AJ, Larson AA, Kuriyama R, Sellitto C, Madl JE (1989) Co-localization of glutamate and tubulin in putative excitatory neurons of the hippocampus and amygdala: an immunohistochemical study using monoclonal antibodies. Neuroscience 30:405421.

McGeer PL, McGeer EG (1989) Amino acid neurotransmitters. In: Basic neurochemistry (Siegel GJ, Agranoff BW, Albers RW, Molinoff PB, eds), pp 311-332. New York: Raven.

Mesulam M-M (1982) Principles of horeseradish peroxidase neurohistochemistry and their applications for tracing neural pathways-axonal transport, enzyme histochemistry and light microscopic analysis. In: Tracing neural connections with horseradish peroxidase (Mesulam M-M, ed), pp 1-151. New York: Wiley.

Montero VM (1990) Quantitative immunogold analysis reveals high glutamate levels in synaptic terminals of retino-geniculate, corticogeniculate, and geniculo-cortical axons in the cat. Vis Neurosci 4: $437-444$.

Montero VM, Wenthold RJ (1989) Quantitativeimmunogold analysis reveals high glutamate levels in retinal and cortical synaptic terminals in the lateral geniculate nucleus of the macaque. Neuroscience 31: 639-647.

Nahin RL (1988) Immunocytochemical identification of long ascending, peptidergic lumbar spinal neurons terminating in either the medial or lateral thalamus in the rat. Brain Res 443:345-349.

Olucha F, Martinez-Garcia F, Lopez-Garcia C (1985) A new stabilizing agent for the tetramethyl benzidine (TMB) reaction product in the histochemical detection of horseradish peroxidase (HRP). J Neurosci Methods 13:131-138.

Ottersen OP (1987) Postembedding light- and electron microscopic immunocytochemistry of amino acids: description of a new model system allowing identical conditions for specificity testing and tissue processing. Exp Brain Res 69:167-174.

Ottersen OP (1989a) Quantitative electron microscopic immunocytochemistry of neuroactive amino acids. Anat Embryol 180:1-15.

Ottersen OP (1989b) Postembedding immunogold labelling of fixed glutamate: an electron microscopic analysis of the relationship be- tween gold particle density and antigen concentration. J Chem Neuroanat $2: 57-66$.

Ottersen OP (1991) Excitatory amino acid neurotransmitters: anatomical systems. In: Excitatory amino acid antagonists (Meldrum BS, ed), pp 14-38. Oxford: Blackwell.

Ottersen OP, Storm-Mathisen J (1984) Glutamate- and GABA-containing neurons in the mouse and rat brain, as demonstrated with a new immunocytochemical technique. J Comp Neurol 229:374-392.

Ottersen OP, Storm-Mathisen J, Madsen S, Skumlien S, Strømhaug J (1986) Evaluation of the immunocytochemical method for amino acids. Med Biol 64:147-158.

Otterscn OP, Laake JH, Storm-Mathisen J (1990a) Demonstration of a releasable pool of glutamate in cerebellar mossy and parallel fibre terminals by means of light and electron microscopic immunocytochemistry. Arch Ital Biol 128:111-125.

Ottersen OP, Storm-Mathisen J, Bramham C, Torp R, Laake J, Gundersen V (1990b) A quantitative electron microscopic immunocytochemical study of the distribution and synaptic handling of glutamate in rat hippocampus. In: Progress in brain research, Vol 83 (Storm-Mathisen J, Zimmer J, Ottersen OP, eds), pp 99-114. Amsterdam: Elsevier.

Ottersen OP, Zhang N, Walberg F (1991) Metabolic compartmentation of glutamate and glutamine: morphological evidence obtained by quantitative immunocytochemistry in rat cerebellum. Neuroscience, in press.

Penny GR, Fitzpatrick D, Schmechel DE, Diamond IT (1983) Glutamic acid decarboxylase-immunoreactive neurons and horseradish peroxidase-labeled projection neurons in the ventral posterior nucleus of the cat and Galago senegalensis. J Neurosci 3:1868-1887.

Peschanski M, Ralston HJ III (1985) Light and electron microscopic evidence of transneuronal labeling with WGA-HRP to trace somatosensory pathways to the thalamus. J Comp Neurol 236:29-41.

Ralston HJ III (1983) The synaptic organization of the ventrobasal thalamus in the rat, cat and monkey. In: Somatosensory integration in the thalamus (Macchi G, Rustioni A, Spreafico R, eds), pp 241250. Amsterdam: Elsevier.

Ralston HJ III (1985) The fine structure of the ventrobasal thalamus of the monkey and cat. Brain Res Rev 9:228-241.

Ralston HJ III, Ohara PT, Ralston DD, Chazal G (1988) The neuronal and synaptic organization of the cat and primate somatosensory thalamus. In: Cellular thalamic mechanisms (Bentivoglio M, Spreafico R, eds), pp 127-141. Amsterdam: Elsevier.

Rustioni A, Weinberg RJ (1989) The somatosensory system. In: Handbook of chemical neuroanatomy, $\mathrm{Vol} 7$, Integrated systems of the CNS, Pt II (Björklund A, Hökfelt T, Swanson LW, eds), pp 219-321. Amsterdam: Elsevier.

Rustioni A, Schmechel DE, Spreafico R, Cheema S, Cuénod M (1983) Excitatory and inhibitory amino acid putative neurotransmitters in the ventralis posterior complex: an autoradiographic and immunocytochemical study in rats and cats. In: Somatosensory integration in the thalamus (Macchi G, Rustioni A, Spreafico R, eds), pp 365-383. Amsterdam: Elsevier.

Rustioni A, Battaglia G, De Biasi S, Giuffrida R (1988) Neuromediators in somatosensory thalamus: an immunocytochemical overview. In: Cellular thalamic mechanisms (Bentivoglio M, Spreafico R, eds), pp 271-296. Amsterdam: Elsevier.

Salt TE (1986) Mediation of thalamic sensory input by both NMDA receptors and non-NMDA receptors. Nature 322:263-265.

Salt TE (1988) Electrophysiological studies of excitatory amino acid neurotransmission in the ventrobasal thalamus. In: Cellular thalamic mechanisms (Bentivoglio M, Spreafico R, eds), pp 297-310. Amsterdam: Elsevier.

Salt TE, Eaton SA (1989) Function of non-NMDA receptors and NMDA receptors in synaptic responses to natural somatosensory stimulation in the ventrobasal thalamus. Exp Brain Res 77:646-652.

Salt TE, Eaton SA (1991) Sensory excitatory postsynaptic potentials mediated by NMDA and non-NMDA receptors in the thalamus in vivo. Eur J Neurosci 3:296-300.

Schönitzer K, Holländer H (1981) Anterograde tracing of horseradish peroxidase (HRP) with the electron microscope using the tetramethylbenzidine reaction. J Neurosci Methods 4:373-383.

Somogyi P, Hodgson AJ (1985) Antisera to $\gamma$-aminobutyric acid. III. Dcmonstration of GABA in Golgi-impregnated neurons and in conventional electron microscopic sections of cat striate cortex. J Histochem Cytochem 33:249-257. 
Somogyi P, Halasy K, Somogyi J, Storm-Mathisen J, Ottersen OP (1986) Quantification of immunogold labelling reveals enrichment of glutamate in mossy and parallel fibre terminals in cat cerebellum. Neuroscience 19:1045-1050.

Spreafico R, Schmechel DE, Ellis LC Jr, Rustioni A (1983) Cortical relay neurons and interneurons in the $n$. ventralis posterolateralis of cats: a horseradish peroxidase, electron-microscopic, Golgi and immunocytochemical study. Neuroscience 9:491-509.

Spreafico R, Amadeo A, De Biasi S (1989) Glutamate immunoreactivity in identified terminals in the ventro postero lateral nucleus of the rat thalamus. Soc Neurosci Abstr 15:384.

Storm-Mathisen J, Ottersen OP (1988) Anatomy of putative glutamatergic neurons. In: Neurotransmitters and cortical function (Avoli M, Reader TA, Dykes RW, Gloor P, eds), pp 39-70. New York: Plenum.
Storm-Mathisen J, Leknes AK, Bore AT, Vaaland JL, Edminson P, Haug F-MS, Ottersen OP (1983) First visualization of glutamate and GABA in neurons by immunocytochemistry. Nature 301:517520.

Zhang N, Walberg F, Laake JH, Meldrum BS, Ottersen OP (1990) Aspartate-like and glutamate-like immunoreactivities in the inferior olive and climbing fibre system: a light microscopic and semiquantitative electron microscopic study in rat and baboon (Papio anubis). Neuroscience 38:61-80.

Zhang N, Laake J, Nagelhus E, Storm-Mathisen J, Ottersen OP (1991) Distribution of glutamine-like immunoreactivity in the cerebellum of the rat and baboon (Papio anubis) with reference to the issue of metabolic compartmentation. Anat Embryol, 184:213-223. 